\title{
New Anacardic Acid-Inspired Benzamides: Histone Lysine Acetyltransferase Activators
}

\author{
José A. Souto, ${ }^{[\mathrm{a}]}$ Rosaria Benedetti, ${ }^{[\mathrm{b}, \mathrm{d}, \mathrm{e}]}$ Katharina Otto, ${ }^{[\mathrm{a}]}$ Marco Miceli, ${ }^{[\mathrm{b}]}$ Rosana Álvarez, ${ }^{*[\mathrm{a}]}$ \\ Lucia Altucci, ${ }^{*[b, c]}$ and Angel R. de Lera* ${ }^{*[a]}$
}

A series of $\mathrm{N}$-(4-cyano-3-trifluoromethyl-phenyl)-2-ethoxy-6alkyl (and alkenyl) benzamides related to the anacardic acid derivative CTPB have been prepared from 2,6-dihydroxybenzoic acid with a Suzuki coupling and addition of the anion of 4cyano-3-trifluoromethylphenylamine to a benzodioxinone as the key steps. In U937 cells, these analogues, in particular 7 c, $\mathbf{7 d}, \mathbf{7} \mathbf{f}$ and $\mathbf{7} \mathbf{j}$, induced cell-cycle arrest in the G1 phase, caused apoptosis in about $20 \%$ of the cells, and increased the acetylation levels of $\mathrm{H} 3$. These activities correlate with the enzymatic activation of histone lysine acetyltransferases (KATs) CBP and PCAF.

\section{Introduction}

Data accumulated over the past decade clearly link cancer onset and tumour progression to the deregulation of the enzymatic machinery responsible for epigenetic modifications of both DNA and histone tails within the nucleosomes-the basic units of chromatin. ${ }^{[1-5]}$ The "epigenetic marks" on chromatin include methylation of DNA at CpG islands, as well as a variety of covalent modifications (notably methylation, acetylation, ADP-ribosylation, phosphorylation, sumoylation and ubiquitylation) of basic amino acid residues located primarily at the tails of histones $\mathrm{H} 3$ and $\mathrm{H}_{4}{ }^{[6]}$ These alterations become docking sites for additional proteins that trigger the assembly of supramolecular structures, ${ }^{[7,8]}$ which among other cellular processes regulate chromatin remodelling, cell cycle, splicing, nuclear transport and actin nucleation. ${ }^{[9-11]}$ The reversible nature of most of the epigenetic modifications ${ }^{[12]}$ has been exploited for the development of novel approaches to cancer ${ }^{[11,13-15]}$ and therapies for other diseases as well. ${ }^{[16]}$

Histone lysine acetyltransferases ${ }^{1}(\mathrm{KATS})^{[17,18]}$ are responsible for the transfer of acetyl groups to lysine residues, whereas histone deacetylases (HDACs) catalyse the reversal of this covalent modification and remove acetyl substituents. Acetylation (but not methylation) weakens the interactions of histone tails with the negatively charged phosphate groups of DNA in the nucleosome, converting the nontranscribed heterochromatin to the more open euchromatin state, which is now accessible to the transcriptional machinery. ${ }^{[19]}$

KATs have been recently grouped into seven families ${ }^{[17,18]}$ although only four of them have intrinsic KAT activities: ${ }^{[20]} \mathrm{Gcn} 5$ and PCAF, which are related to the yeast KAT; the cyclic adenosine monophosphate response element-binding protein (CREB) binding protein (CBP) and p300, which act as coactivators for a

\footnotetext{
${ }^{1}$ Traditionally histone acetyltransferases were abbreviated as HATs, however, to reflect their general activity beyond that on histone, the preferred abbreviation for lysine $(K)$ acetyltransferases is now KATs. Further details on this change in nomenclature are given in Reference [17].
}

number of transcription factor complexes; ${ }^{[21]}$ TAF250, which is part of the basic transcription complex TFIID that binds to the TATA box; and finally SRC- 1 and ACTR, which are coactivators for the ligand-activated nuclear receptors, and their KAT activities are controversial. ${ }^{[21-23]}$

Although all KAT enzymes require acetyl-CoA as a cofactor, the precise mechanism of acetyl transfer to the lysine residue by the KAT enzyme ${ }^{[20,24]}$ might vary with isoform. A ternary complex, a "ping-pong" and a "hit and run" mechanism have been proposed. ${ }^{[16]}$ Regardless of the mechanistic details, dysfunction of acetyltransferase enzymatic activity has been associated to several diseases, including cancer, Huntington's disease, inflammatory disease, diabetes mellitus and AIDS. ${ }^{[17]}$ Restoring the balance between acetylation and deacetylation via small-molecule modulation might correct aberrant cell growth and differentiation. ${ }^{[25]}$ In fact, inhibitors of HDACs display anticancer actions, ${ }^{[4,26,27]}$ and two drugs-SAHA (also known as vorinostat or Zolinza ${ }^{\circledR}$ ) and FK228 (also known as romidepsin or Istodax ${ }^{\circledR}$ - -are in the clinic for the treatment of cutaneous

[a] Dr. J. A. Souto, K. Otto, Prof. Dr. R. Álvarez, Prof. Dr. A. R. de Lera Departamento de Química Orgánica, Facultade de Química, Universidade de Vigo, Campus As Lagoas-Marcosende, 36310 Vigo (Spain) Fax: (+34) 986-811-940

E-mail:rar@uvigo.es qolera@uvigo.es

[b] R. Benedetti, M. Miceli, Prof. Dr. L. Altucci Dipartimento di Patologia Generale, Seconda Università degli Studi di Napoli, Vico L. de Crecchio 780138 Napoli (Italy)

Fax: (+39) 081-450-169

E-mail: lucia.altucci@unina2.it

[c] Prof. Dr. L. Altucci

IGB-CNR, Via Pietro Castellino, 80100 Napoli (Italy)

[d] R. Benedetti

Dipartimento di Fisica, Università di Napoli Federico II, Napoli (Italy)

[e] R. Benedetti

Dipartimento di Chimica Organica e Biochimica, Università di Napoli Federico II, Napoli (Italy) 
T-cell lymphomas. Modulators of KATs (inhibitors or activators) also have the potential to become new generation therapeutics. ${ }^{[16]}$

KAT modulators of different structural classes, both of natural and synthetic origin, have been described in the literature (Figure 1). ${ }^{[16]}$ Bisubstrate analogues, such as LysCoA (1) and H3CoA-20 (2) act as inhibitors of p300 and PCAF/MYST Esa1/ Tip60, respectively. ${ }^{[28]}$ Inhibitors discovered by virtual ligand

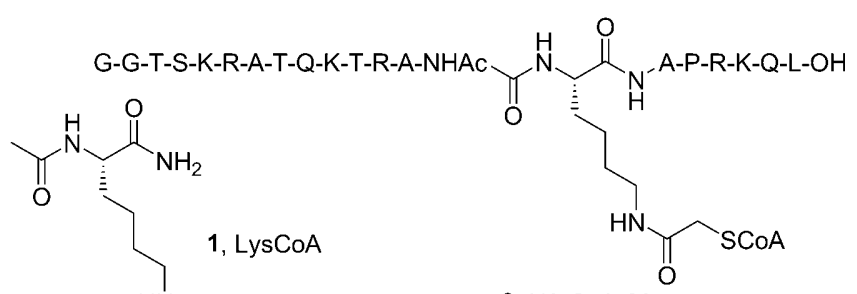<smiles>N#CSCC(=O)NCCO</smiles>

2, H3-COA-20<smiles>CC1=NN(c2ccc(C(=O)O)cc2)C(=O)/C1=C\c1ccc(-c2cc(C)c(C)cc2[N+](=O)[O-])o1</smiles>

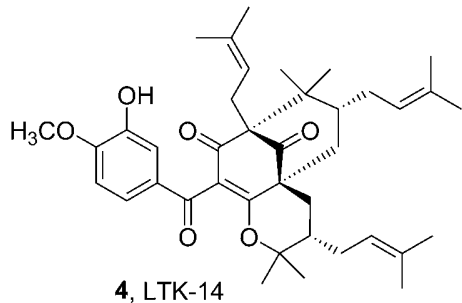

4, LTK-14

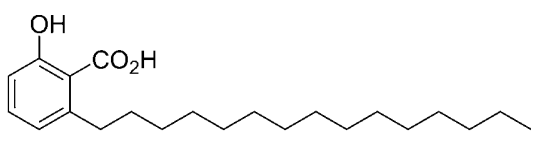

$\mathbf{5}$, anacardic acid (AA)

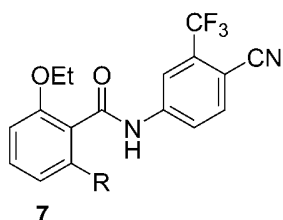<smiles>[R]Oc1cccc(C(C)(C)C)c1C(=O)Nc1ccncc1</smiles>

a, $\mathrm{R}=\mathrm{C}_{8} \mathrm{H}_{17}$

$\mathrm{b}, \mathrm{R}=\mathrm{C}_{10} \mathrm{H}_{21}$
$\mathrm{c}, \mathrm{R}=\mathrm{C}_{7} \mathrm{H}_{15}$

d, $\mathrm{R}=\mathrm{C}_{6} \mathrm{H}_{13}$

e, $\mathrm{R}=\left(\mathrm{CH}_{2}\right)_{4} \mathrm{CH}_{2} \mathrm{OH}$

f, $\mathrm{R}=\left(\mathrm{CH}_{2}\right)_{3} \mathrm{CH}_{2} \mathrm{OH}$

g, $\mathrm{R}=\left(\mathrm{CH}_{2}\right)_{2} \mathrm{CH}_{2} \mathrm{OH}$

h, $\mathrm{R}=(E)-(\mathrm{CH}=\mathrm{CH})-p-\mathrm{CF}_{3}-\mathrm{C}_{6} \mathrm{H}_{4}$

, $\mathrm{R}=(E)-(\mathrm{CH}=\mathrm{CH})-m-\mathrm{Br}-\mathrm{C}_{6} \mathrm{H}_{4}$

j, $\mathrm{R}=(E)-(\mathrm{CH}=\mathrm{CH})-\mathrm{C}_{6} \mathrm{H}_{5}$

$\mathrm{k}, \mathrm{R}=(E)-(\mathrm{CH}=\mathrm{CH})-\left(\mathrm{CH}_{2}\right)_{3} \mathrm{CH}_{2} \mathrm{OH}$

Figure 2. Anacardic acid-inspired amides.

Since the strongest KAT inhibitors ( $7 \mathrm{a}$, with an octyl group being the most potent) had the shortest hydrophobic alkyl chains of the series of CTPB analogues, ${ }^{[35]}$ we decided to further reduce the size of the chain and incorporate terminal polar and/or unsaturated groups in the same position of the C6-salicylic amide substituent, while preserving the ethoxy ${ }^{[32]}$ and the 4-cyano-3-trifluoromethylbenzamide functionalities. $^{[32,35]}$

\section{Results and Discussion}

\section{Synthesis}

Following the synthetic approach to the CTPB analogues that uses a Suzuki cross-coupling reaction ${ }^{[37]}$ between an aryl triflate and different trialkylboranes, ${ }^{[38]}$ known triflate $9^{[39,35]}$ containing a 1,3-benzodioxinone group ${ }^{[40-42]}$ was coupled to the trialkylborane obtained by hydroboration of the terminal alkene with 9-BBN in the presence of $\mathrm{PdCl}_{2}(\mathrm{dppf}), \mathrm{MeONa}$ and $\mathrm{KBr} \cdot{ }^{[42]}$ Five

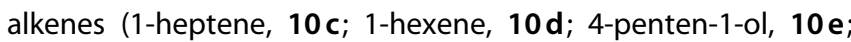
3-buten-1-ol, $\mathbf{1 0} \mathbf{f}$; 2-propen-1-ol, $\mathbf{1 0} \mathbf{g}$ ) were selected as precursors of the organoboranes. The combined yields for the hydroboration/coupling step ranged from 39 to $66 \%$.

The acyl transfer/dioxinone deprotection step required the treatment of the corresponding aniline 12 with $n B u L i$ in DMPU and heating with 11 at $80^{\circ} \mathrm{C}$, as reported for ester formation starting from similar substrates. ${ }^{[43]}$ Formation of the ethyl ether from salicylamides $\mathbf{1 3}$ provided the final benzamides $\mathbf{7} \mathbf{c}, \mathbf{d}$ and the protected primary alcohols $14 \mathbf{e}-\mathbf{g}$, which were deprotected to afford $7 \mathbf{e}-\mathbf{g}$ upon treatment with tetra- $n$-butylammonium fluoride (TBAF) in THF (Scheme 1; Table 1). 


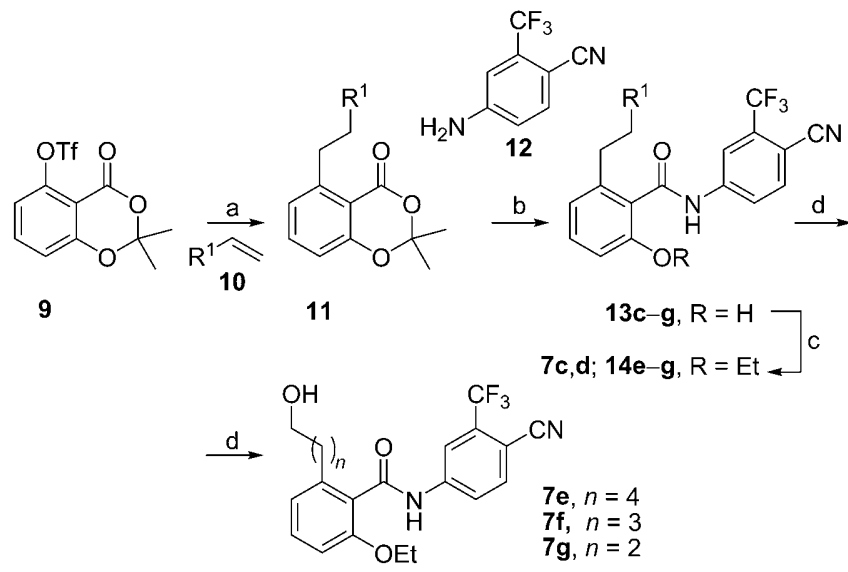

Scheme 1. Reagents and conditions: a) 10 c-g, 9-BBN, $\mathrm{MeONa}, \mathrm{PdCl}_{2}(\mathrm{dppf})$, $\mathrm{KBr}, 70{ }^{\circ} \mathrm{C}$, THF; b) Aniline 12, nBuLi, DMPU, $80^{\circ} \mathrm{C}, 2 \mathrm{~h}$; c) $\mathrm{Et}_{2} \mathrm{SO}_{4}, \mathrm{~K}_{2} \mathrm{CO}_{3}$, acetone; d) TBAF, THF. The yield for each step is given in Table 1.

\begin{tabular}{|c|c|c|c|c|c|c|c|c|}
\hline \multirow[t]{2}{*}{$\mathrm{R}^{1}$} & \multicolumn{2}{|c|}{ Step a } & \multicolumn{2}{|c|}{ Step b } & \multicolumn{2}{|c|}{ Step c } & \multicolumn{2}{|c|}{ Step d } \\
\hline & $\mathrm{P}$ & [\%] & $\mathrm{P}$ & [\%] & $\mathrm{P}$ & [\%] & $P$ & {$[\%]$} \\
\hline $\mathrm{C}_{5} \mathrm{H}_{11}$ & $11 \mathrm{c}$ & 39 & $13 c$ & 76 & $7 c$ & 76 & & - \\
\hline $\mathrm{C}_{4} \mathrm{H}_{9}$ & $11 \mathrm{~d}$ & 41 & $13 d$ & 65 & $7 d$ & 46 & & - \\
\hline$\left(\mathrm{CH}_{2}\right)_{2} \mathrm{CH}_{2} \mathrm{OTBS}$ & $11 \mathrm{e}$ & 32 & $13 e$ & 35 & & & $7 e$ & $61^{[\mathrm{b}]}$ \\
\hline $\mathrm{CH}_{2} \mathrm{CH}_{2} \mathrm{OTBS}$ & $11 \mathrm{f}$ & 66 & $13 f$ & 50 & & & $7 f$ & $51^{[b]}$ \\
\hline $\mathrm{CH}_{2} \mathrm{OTBS}$ & $11 \mathrm{~g}$ & 32 & $13 \mathrm{~g}$ & 37 & & - & $7 \mathrm{~g}$ & $97^{[b]}$ \\
\hline
\end{tabular}

[a] The product (P) and associated yield (\%) is given for each step. $R^{1}$ introduced using compounds 10 (see Scheme 1). [b] Combined yield for steps $\mathrm{c}$ and $\mathrm{d}$.

A reversal of the strategic key steps is also possible, and this strategy was employed for the synthesis of the C6-unsaturated salicylamides $\mathbf{7 h}-\mathbf{k}$. The 1,3-benzodioxinone $\mathbf{1 5}$ derived from 2,6-dihydroxybenzoic acid ${ }^{[40-42]}$ (the precursor to triflate 9) was converted into the ethyl ether 16 as described above (91\% yield). Addition of the anion derived from aniline 12 to 16 effected the acyl transfer/deprotection ${ }^{[43]}$ in $88 \%$ yield. Triflate 18 was obtained in $87 \%$ yield upon treating 17 with trifluoroacetic anhydride (TFAA) in pyridine at $25^{\circ} \mathrm{C}$ (Scheme 2).

The alkenylboron reagents required for the completion of the series of C6-unsaturated salicylamides were acquired following complementary methods. (E)-Alkenyl boronates $20 \mathbf{a}, \mathbf{b}$ were obtained in high yield and excellent stereoselectivity from commercially available benzaldehydes $19 \mathbf{a}, \mathbf{b}$ using the Takai-Utimoto condensation reaction, ${ }^{[4]}$ after activation of 2(dichloromethyl)pinacolboronate with chromium(II) in the presence of lithium iodide. ${ }^{[45]}$ Two previously described alkenylboron reagents $21^{[46]}$ and $22^{[47]}$ were obtained by the hydroboration of the precursor alkynes and hydrolysis for 22.

The Suzuki coupling of triflate 18 and organoboranes 20-22 was complete after about $15 \mathrm{~min}$ in concentrated solutions $(0.2 \mathrm{M})$ using microwave irradiation. ${ }^{[48,49]}$ Unfortunately, the instability of pinacolboronates $\mathbf{2 0}$ under the reaction conditions decreased the yield of the corresponding products $\mathbf{7} \mathbf{h}$ and $\mathbf{7} \mathbf{i}$.<smiles>[R]C=Cc1cccc(OCC)c1C(=O)Nc1ccc(C#N)c(C(F)(F)F)c1</smiles>
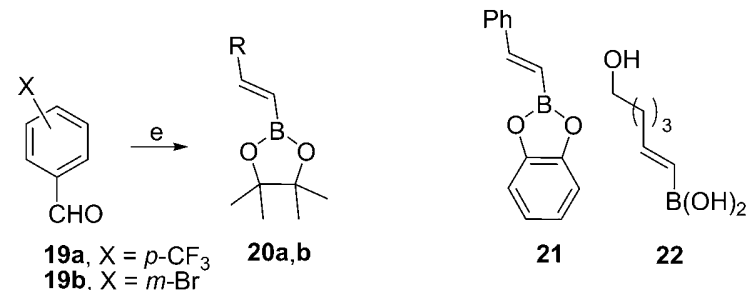

Scheme 2. Reagents and conditions: a) Etl, $\mathrm{K}_{2} \mathrm{CO}_{3}$, acetone, $25^{\circ} \mathrm{C}, 12 \mathrm{~h}, 91 \%$; b) 12, nBuLi, DMPU, $80^{\circ} \mathrm{C}, 2 \mathrm{~h}, 88 \%$; c) TFAA, pyridine, $25^{\circ} \mathrm{C}, 87 \%$; d) 20 a,b, 21 or $22, \mathrm{Pd}\left(\mathrm{PPh}_{3}\right)_{4}, \mathrm{~K}_{2} \mathrm{CO}_{3}$, dioxane, microwave, $85^{\circ} \mathrm{C}, 15 \mathrm{~min}(\mathbf{7}, \mathbf{h}, 43$; $7 \mathbf{i}$, $27 \%$; 7 j, $80 \%$; 7 k, $92 \%)$; e) 2-(Dichloromethyl)pinacolboronate, $\mathrm{CrCl}_{2}$, Lil, THF, $25^{\circ} \mathrm{C}, 16 \mathrm{~h}(20 \mathrm{a}, 81 \% ; 20 \mathrm{~b}, 91 \%)$.

\section{Biological evaluation}

To evaluate whether these novel CTPB-inspired benzamides are able to have an effect on KAT activity, we tested the compounds in enzymatic and whole-cell assays. In particular, cellbased assays were performed in U937 leukaemia cells to determine the antiproliferative potential and the ability of the synthetic compounds to alter the cell cycle. Compared with the vehicle-treated cells (negative control) and to the cells treated with the pan-HDAC inhibitor SAHA, used as a positive control for its known actions on cell cycle and apoptosis, ${ }^{[50]}$ at $5 \mu \mathrm{M}$ the test compounds did not significantly alter the cell cycle. In contrast to SAHA, which accumulates the cell population in the $\mathrm{S}$ phase after $24 \mathrm{~h}$ of treatment, at the same concentration the synthetic salicylamides showed only a modest effect $(\sim 10 \%$ increase of U937 cells in the S phase; Figure $3 \mathrm{a})$. However, after $24 \mathrm{~h}$ of induction, compounds $7 \mathrm{c}-\mathrm{e}$ and $\mathbf{7 k}$ at $50 \mu \mathrm{M}$ induced a time-dependent accumulation of U937 cells in the $\mathrm{G} 1$ phase that reached $70 \%$ (Figure $3 \mathrm{~b}$ ), doubling the effect of the controls SAHA and AA (5). The parent compound CTPB (6) had no effect on the cell cycle at the tested concentrations of 5 and $50 \mu \mathrm{M}$. The failure of $\mathbf{5}$ to influence the cell cycle regardless of its concentration (see Figure $3 \mathrm{a}$ and $3 \mathrm{~b}$ ) is consistent with reports on its inability to pass through the cell membrane. ${ }^{[51]}$ In contrast, some of the salicylamides altered the cell cycle, entering cells most likely due to the presence of functionalities that provide greater membrane permeability. In addition, the series of compounds induced a $\sim 20 \%$ apoptosis in U937 cells (Figure 3). 

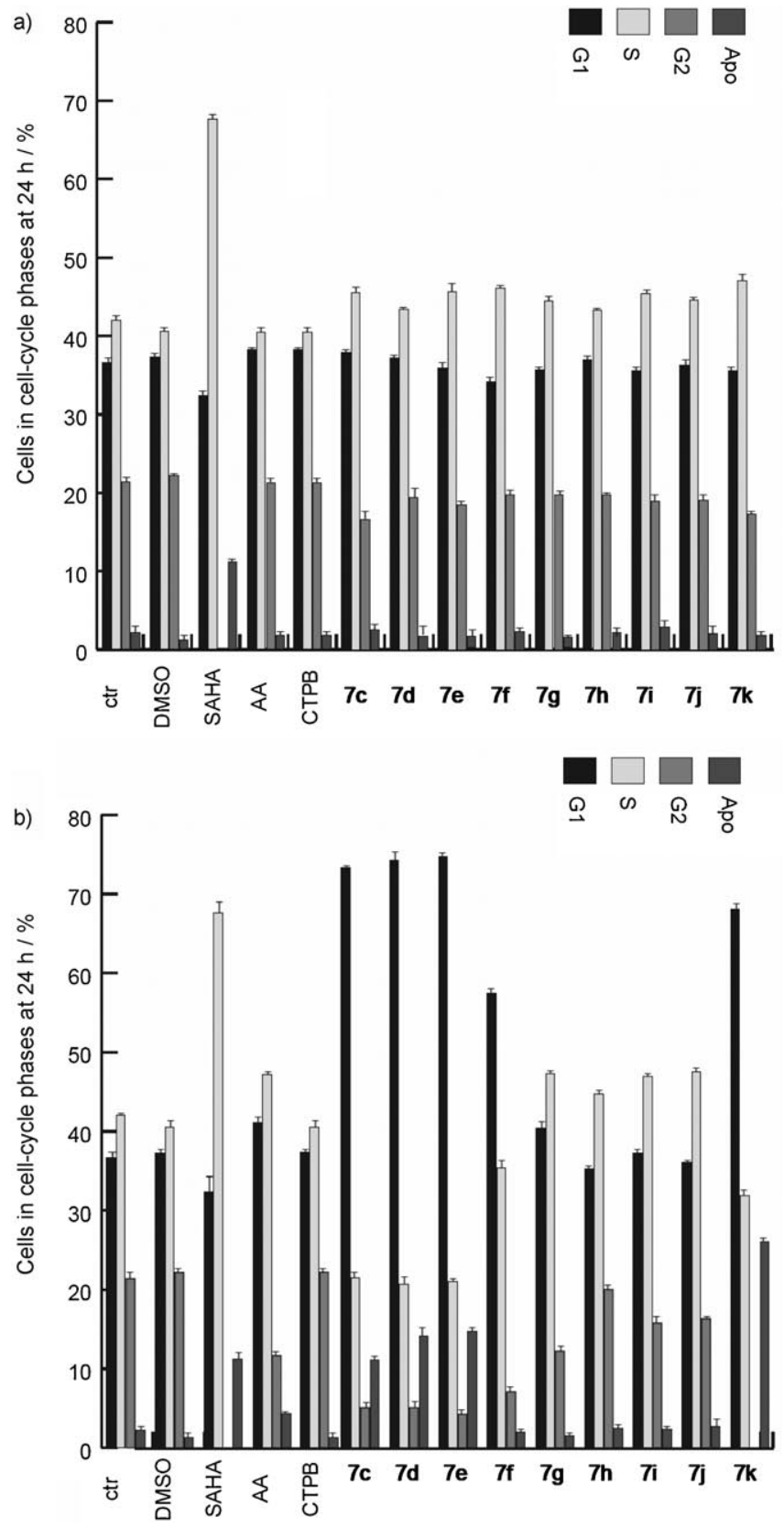

Figure 3. a) Cell-cycle analysis of U937 cells treated with the indicated compounds at $5 \mu \mathrm{m}$ for $24 \mathrm{~h}$. b) Cell-cycle analysis of U937 cells treated with the indicated compounds at $50 \mu \mathrm{m}$ for $24 \mathrm{~h}$. Cell-cycle phases (G1, S and S2) and apoptosis (Apo) are shown. The data represent the mean of three independent experiments.

To confirm the general involvement of these CTPB analogues in the modulation of KAT activity; we analysed the acetylation status of the representative histone protein $\mathrm{H} 3$, which is dependent upon the opposing activities of HDAC and KAT enzymes (Figure $4 \mathrm{a}$ ). The activities of these AA-derived benzamides were compared to those of AA $(50 \mu \mathrm{M})$, CTPB $(50 \mu \mathrm{M})$, and the HDAC inhibitors SAHA (5 $\mu \mathrm{M})$ and MS-275 (5 $\mu \mathrm{M})$. The inhibition of HDACs is demonstrated by an increase in the global level of acetyl groups on $\mathrm{H} 3$ lysine tails after treatment of U937 cells for $24 \mathrm{~h}$ (Figure $4 \mathrm{a}$ ), in comparison to the control experiments using SAHA and MS-275. Despite the reported low cell permeability, CTPB 6 is able to induce an increase in the acetylation of $\mathrm{H} 3$ lysine tails due to its action on KAT enzymes (Figure 4a). Interestingly, a similar effect was observed with most of the salicylamides at $50 \mu \mathrm{M}$ (Figure $4 \mathrm{a}$ ). This effect can most likely be ascribed to the increase of KAT activity and the up-regulation of the acetylation reaction. Compounds $7 \mathrm{c}$, $\mathbf{7 e}, \mathbf{7} \mathbf{f}$ and $\mathbf{7 k}$, which showed induction of KAT activity, also caused significant cell-cycle arrest in the G1 phase (see Figure $3 \mathrm{a}$ and $3 \mathrm{~b}$, and Figure $4 \mathrm{a}$ ). The insensitivity of the intracellular acetylation status to the presence of $A A$, as deduced from Western blot analysis, further confirms its well-known inability to enter the cells.

To evaluate the effective induction of KAT activity, two enzymatic assays were performed: a PCAF and a CBP radioactive assay. Figure 4 shows the correlation between the enzymatic and whole-cell assay results. The CTPB analogues, in particular 7e, $\mathbf{7} \mathbf{f}, \mathbf{7} \mathbf{h}, \mathbf{7 k}$, enhanced the CBP acetyltransferase activity by $30-40 \%$ relative to the control (Figure $4 \mathrm{~b}$ ). In our previous report, we determined that benzamides $7 \mathbf{a}$ and $\mathbf{7 b}$, with an $n$-octyl and $n$-decyl chains at C6, respectively, behaved as modest inhibitors of p300. Indeed, the shorter homologue $7 c$ is a rather weak inhibitor of CBP, but the $n$-hexyl derivative $\mathbf{7 d}$ is inactive, thus signalling the lower limit for modifications at that position with saturated groups. ${ }^{[35]}$

Likewise, all the compounds in the series induced activation of PCAF in the radioactive enzymatic assay. Indeed these compounds enhanced the PCAF activity by at least $150 \%$, and in particular $\mathbf{7 e}, \mathbf{7} \mathbf{f}, \mathbf{7} \mathbf{g}$ and $\mathbf{7 ~ k}$ induced a 200-250-fold activation relative to the control (Figure $4 \mathrm{c}$ ). In both assays, AA behaves as a very potent enzymatic inhibitor, ${ }^{[32,51]}$ whereas benzamide CTPB 6 is a selective activator of p300/CBP (Figure 4b, 4c and $4 \mathrm{~d})$ as previously described. ${ }^{[32,34]}$ On the contrary, benzamides 7 activate KATs and, moreover, exhibit a preference for the PCAF family. These experiments confirm that the analogues are able to modulate the acetylation balance inside the cell by the direct activation of KAT enzymes.

\section{Conclusions}

The development of chemical probes and modulators of KATs has provided valuable insights into the catalytic features of this enzyme class and revealed their roles in various cellular pathways. ${ }^{[16]}$ The great majority of these modulators are KAT inhibitors with various degrees of potency, selectivity and cell permeability. As far as we know, only the AA-derived benzamide CTPB is an activator of the p300/CBP KAT. However, no drugs have been described that selectively distinguish between the subtypes $\mathrm{p} 300$ and CBP or PCAF and GCN5. As a follow-up of our previous studies on the activities of AA-derived CTPB analogues, ${ }^{[35]}$ we have designed and synthesised a new series of compounds, which carry polar terminal groups to improve the permeability and enhance their activity. From the analysis of the biological readouts, we conclude that these amides act specifically on KAT enzymes both in enzymatic and whole-cell assays. The increase in KAT activity was $\sim 30 \%$ for CBP and $\sim 200 \%$ for PCAF when the compounds, in particular those with a primary alcohol on the side chain $7 e$ and $7 k$, 
a)

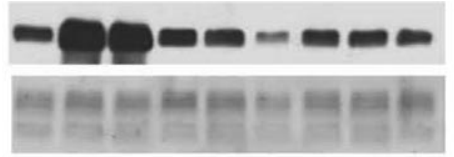

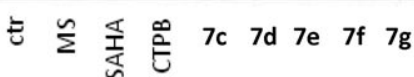

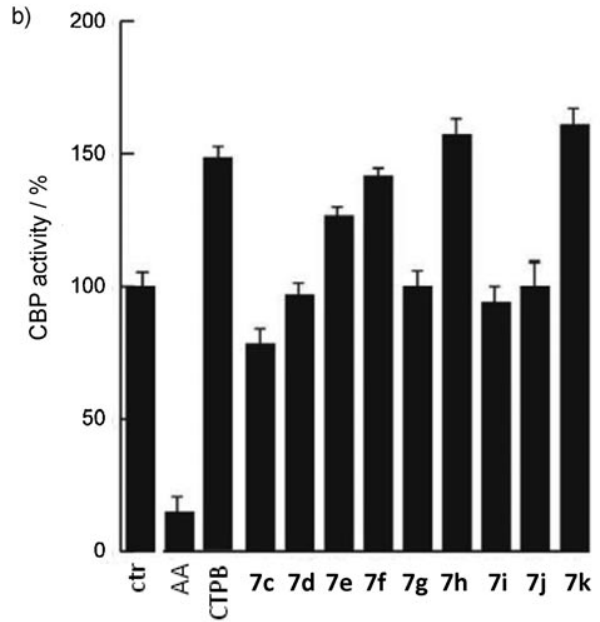

$\mathrm{AcH} 3$

Ponceau red

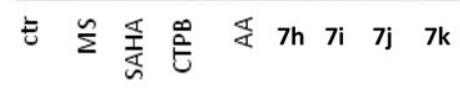

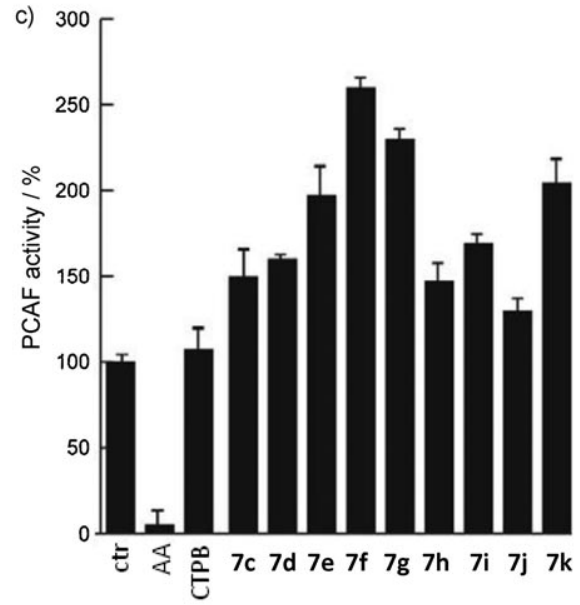

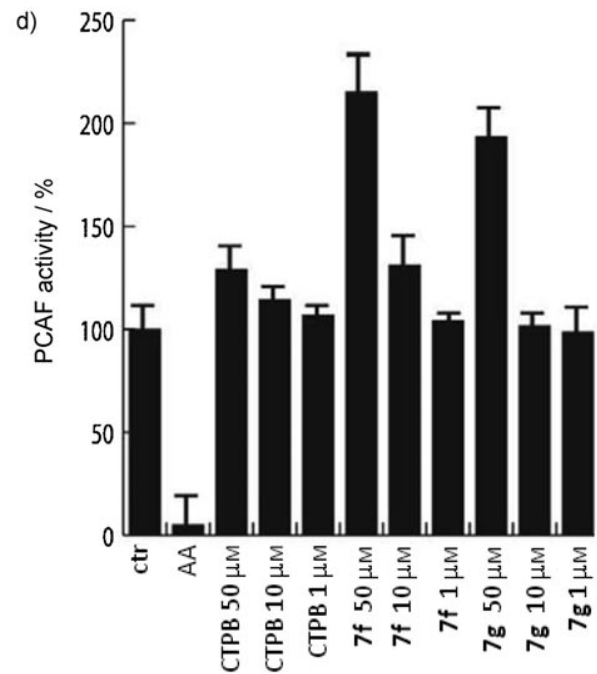

Figure 4. a) Western Blot analysis of histone $\mathrm{H} 3$ acetylation carried out in U937 cells after $24 \mathrm{~h}$ induction with compounds at $50 \mu \mathrm{M}$. b) CBP radioactive assay performed with $1 \mu \mathrm{g}$ of recombinant CBP enzyme. The compounds were tested at $50 \mu \mathrm{M}$ and the CBP activity (\%) was compared in each case to anacardic acid (AA; 5) and CTPB (6) at the same concentration. C) PCAF radioactive assay performed with $200 \mathrm{ng}$ of recombinant PCAF enzyme. The compounds were tested at $50 \mu \mathrm{M}$ and the inhibition value was reported as a percentage of residual activity in comparison to the control, to anacardic acid (AA; 5) and to CTPB (6). The data represent the mean of three independent experiments. d) PCAF dose-response assay with the selected compounds (5 and $\mathbf{6}$ as reference compounds) at three different concentrations $(50 \mu \mathrm{M}, 10 \mu \mathrm{M}$ and $1 \mu \mathrm{M})$.

were used at $50 \mu \mathrm{m}$. At the same concentration they also showed cell-cycle arrest in the G1 phase and a strong induction of acetylation of $\mathrm{H} 3$ tails.

From the limited number of CTPB-related compounds reported $^{[32,34-36]}$ the modifications at the C6-position have proved most informative:

1) Shorter saturated side chain benzamides $7 \mathbf{a}, \mathbf{7} \mathbf{b}$ (Figure 2) revert the modulatory profile of the parent CTPB $(6)^{[32,34]}$ and behave as p300 inhibitors similar to anacardic acid (5)..$^{[35]}$
2) Further reduction in the size of the alkyl chain $(\mathbf{7 c}, \mathbf{7 d})$ was inconsequential, thus demonstrating a lower limit for modifications at that position.

3) The incorporation of hydroxy groups at the terminus of the C6-group $(\mathbf{7 e}, \mathbf{7} \mathbf{f}, \mathbf{7} \mathbf{g}$ $7 \mathbf{k}$ ) modified the KAT inhibitory activities of the alkylbenzamide analogues $7 \mathrm{a}, 7 \mathrm{~b}$ and provided activators of both p300 and PCAF (Figure 4).

4) In contrast to CTPB (6), these compounds (most notably $\mathbf{7} \mathbf{f}$ and $\mathbf{7 g}$ ) exhibit a preference for the activation of PCAF over p300, thus modifying the selectivity of parent 6 .

An examination of the biological results indicates the lack of a linear correlation between the enzymatic and whole-cell data for every compound. In fact, some of the CTPB analogues show a strong G1 phase blockade but not a direct activation of PCAF and/or CBP. The existence of ancillary mechanisms and additive pathways by which the balance of acetylated/deacetylated histones within a cell is maintained, in addition to the chemical structure of the compound itself, might partially explain some of the differences.

Given that the compounds showing a well-defined KAT activation profile $(\mathbf{7} \mathbf{e}, \mathbf{7} \mathbf{f}, \mathbf{7} \mathbf{g}, \mathbf{7} \mathbf{k})$ act at a quite high concentration $(50 \mu \mathrm{M})$, additional chemical modifications of the general scaffold might provide more potent activators that could become valuable tools for understanding the correlation between the acetylation status of histones and nonhistone proteins, and transcriptional activation.

\section{Experimental Section}

\section{Chemistry}

General Procedures: Solvents were dried according to published methods and distilled before use. All other reagents were commer- 
cial compounds of the highest purity available. All reactions were carried out under argon atmosphere, and those not involving aqueous reagents were carried out in oven-dried glassware. Analytical thin-layer chromatography (TLC) was performed on aluminium plates with Merck kieselgel $60 \mathrm{~F}_{254}$ and visualised by UV irradiation $(254 \mathrm{~nm})$ or by staining with solution of phosphomolibdic acid. Flash column chromatography was carried out using Merck kieselgel 60 (230-400 mesh) under pressure. UV/VIS spectra were recorded on a Cary 100 bio-spectrophotometer. Infrared (IR) spectra were obtained on a JASCO FTIR 4200 spectrophotometer from a thin film deposited onto a $\mathrm{NaCl}$ glass. Mass Spectra (MS) were obtained on a Hewlett-Packard HP59970 instrument operating at $70 \mathrm{eV}$ by electron ionisation. High-resolution mass spectra (HRMS) were taken either on a VG Autospec instrument, a Micromass GC-TOF or a Bruker FT-MS apex-Qe. ${ }^{1} \mathrm{H}$ NMR spectra were recorded in $\mathrm{CDCl}_{3}$ and $\left(\mathrm{CD}_{3}\right)_{2} \mathrm{CO}$ at room temperature on a Bruker $\mathrm{AMX}-400$ spectrometer at $400 \mathrm{MHz}$ with residual protic solvent as the internal reference $\left(\mathrm{CDCl}_{3}, \delta_{\mathrm{H}}=7.26 \mathrm{ppm} ;\left(\mathrm{CD}_{3}\right)_{2} \mathrm{CO}, \delta_{\mathrm{H}}=2.05 \mathrm{ppm}\right)$; chemical shifts $(\delta)$ are given in parts per million (ppm), and coupling constants $(J)$ are given in Hertz $(\mathrm{Hz})$. The proton spectra are reported as follows: $\delta$ (multiplicity, coupling constant $J$, number of protons). ${ }^{13} \mathrm{C}$ NMR spectra were recorded in $\mathrm{CDCl}_{3}$ and $\left(\mathrm{CD}_{3}\right)_{2} \mathrm{CO}$ at room temperature on the same spectrometer at $100 \mathrm{MHz}$, with the central peak of $\mathrm{CDCl}_{3}\left(\delta_{\mathrm{C}}=77.0 \mathrm{ppm}\right)$ or $\left(\mathrm{CD}_{3}\right)_{2} \mathrm{CO}\left(\delta_{\mathrm{C}}=30.8 \mathrm{ppm}\right)$ as the internal reference. Although DEPT 135 was used to aid the assignment of signals in the ${ }^{13} \mathrm{C}$ NMR spectra, the multiplicity is only shown for fluorine-carbon bonds, with the $J_{C-F}$ values measured.

2,2-Dimethyl-5-heptyl-4H-1,3-benzodioxin-4-one (11 c): General procedure for the alkyl Suzuki coupling reaction (Method A). A solution of $10 \mathrm{c}(0.09 \mathrm{~mL}, 0.65 \mathrm{mmol})$ in THF $(0.6 \mathrm{~mL})$ was treated with 9-BBN $(1.3 \mathrm{~mL}, 0.5 \mathrm{M}$ in $\mathrm{THF}, 0.65 \mathrm{mmol})$ and the reaction was stirred at $25^{\circ} \mathrm{C}$ for $24 \mathrm{~h}$. The mixture was transferred to a flask containing MeONa $(0.035 \mathrm{~g}, 0.65 \mathrm{mmol})$ and the solution was stirred for $2 \mathrm{~h}$. A mixture of dichloro-1,1'-bis-(diphenylphosphino)ferrocene palladium $(0.006 \mathrm{~g}, 0.018 \mathrm{mmol}), \mathrm{KBr}(0.087 \mathrm{~g}, 0.728 \mathrm{mmol})$ and 9 $(0.2 \mathrm{~g}, 0.61 \mathrm{mmol})$ in THF $(4 \mathrm{~mL})$ was added and the mixture was stirred at $70^{\circ} \mathrm{C}$ for $4 \mathrm{~h}$. Hexane $(1 \mathrm{~mL})$, aq $\mathrm{NaOH}(1 \mathrm{~mL}, 2 \mathrm{M})$ and $\mathrm{H}_{2} \mathrm{O}_{2}(1 \mathrm{~mL}, 30 \% \mathrm{w} / \mathrm{w})$ were then added and the mixture was stirred at $25^{\circ} \mathrm{C}$. The aqueous layer was extracted with $\mathrm{Et}_{2} \mathrm{O}(\times 3)$ and the combined organic layers were washed with a saturated aq $\mathrm{NaHCO}_{3}(\times 3)$ and dried $\left(\mathrm{Na}_{2} \mathrm{SO}_{4}\right)$, and the solvent was evaporated. The residue was purified by column chromatography (90:10, hexane/EtOAc) to afford $11 \mathrm{c}$ as a yellow oil $(70 \mathrm{mg}, 39 \%)$ : ${ }^{1} \mathrm{H}$ NMR $\left(400 \mathrm{MHz}, \mathrm{CDCl}_{3}\right): \delta=7.37(\mathrm{t}, J=7.9 \mathrm{~Hz}, 1 \mathrm{H}), 6.91(\mathrm{~d}, J=7.6 \mathrm{~Hz}, 1 \mathrm{H})$, $6.78(\mathrm{~d}, J=8.2 \mathrm{~Hz}, 1 \mathrm{H}), 3.07(\mathrm{t}, J=7.7 \mathrm{~Hz}, 2 \mathrm{H}), 1.67\left(\mathrm{~s}, 6 \mathrm{H}, 2 \mathrm{CH}_{3}\right)$, $1.6-1.5(\mathrm{~m}, 2 \mathrm{H}), 1.5-1.2(\mathrm{~m}, 8 \mathrm{H}), 0.85 \mathrm{ppm}(\mathrm{t}, J=6.5 \mathrm{~Hz}, 3 \mathrm{H})$; ${ }^{13} \mathrm{C} \mathrm{NMR}\left(100 \mathrm{MHz}, \mathrm{CDCl}_{3}\right): \delta=160.2,157.1,148.5,135.0,125.1$, 115.0, 112.1, 104.9, 34.4, 31.8, 31.2, 29.6, 29.1, 25.6 (2C), 22.6, 14.1 ppm; IR (NaCl): $\tilde{v}=2998(\mathrm{w}, \mathrm{C}-\mathrm{H}), 2954(\mathrm{~m}, \mathrm{C}-\mathrm{H}), 2926$ (s, CH), $2856(\mathrm{~m}, \mathrm{C}-\mathrm{H}), 1738(\mathrm{~s}, \mathrm{C}=\mathrm{O}), 1605(\mathrm{~m}, \mathrm{C}=\mathrm{C}), 1582 \mathrm{~cm}^{-1}(\mathrm{C}=\mathrm{C})$; MS (ESI+): $m / z(\%): 276[M]^{+}$(7), $219(12), 218(100), 176(14), 162$ (38), 161 (20), 148 (13), 147 (43), 134 (77), 133 (11), 105 (34), 91 (11), 77 (11); HRMS (ESI+): $\mathrm{m} / \mathrm{z}[\mathrm{M}]^{+}$calcd for $\mathrm{C}_{17} \mathrm{H}_{24} \mathrm{O}_{3}: 276.1725$, found: 276.1733 .

\section{$\mathrm{N}$-(4-Cyano-3-trifluoromethylphenyl)-6-heptyl-2-hydroxybenz-}

amide $(13 \mathrm{c})$ : General procedure for the amidation of dioxinones. A cooled $\left(0^{\circ} \mathrm{C}\right)$ solution of $12(0.4 \mathrm{~g}, 2.15 \mathrm{mmol})$ and 1,3-dimethyl3,4,5,6-tetrahydro-2 $(1 \mathrm{H})$-pyrimidinone (DMPU; $0.38 \mathrm{~mL}, 3.14 \mathrm{mmol}$ ) in THF $(8.3 \mathrm{~mL})$ at $0^{\circ} \mathrm{C}$ was treated with $n B u L i ~(1.5 \mathrm{~mL}, 1.40 \mathrm{M}$ in hexane, $2.15 \mathrm{mmol}$ ). After stirring for $30 \mathrm{~min}$ at $25^{\circ} \mathrm{C}$ a solution of $11 \mathrm{c}(0.12 \mathrm{~g}, 0.43 \mathrm{mmol})$ in THF $(8.3 \mathrm{~mL})$ was added and the reaction was stirred at $80^{\circ} \mathrm{C}$ for $2 \mathrm{~h}$. Water was added, the layers were separated and the aqueous layer was extracted with EtOAc $(\times 3)$. The combined organic layers were washed with $10 \%$ aq $\mathrm{HCl}(\times 1)$, water $(\times 2)$ and brine $(\times 1)$, dried $\left(\mathrm{Na}_{2} \mathrm{SO}_{4}\right)$ and the solvent was evaporated. The residue was purified by column chromatography (85:15, hexane/EtOAc) to afford $13 \mathrm{c}$ as a yellow oil $(133 \mathrm{mg}, 76 \%)$; $\mathrm{mp}: 147^{\circ} \mathrm{C}$ (hexane/acetone); ${ }^{1} \mathrm{H} \mathrm{NMR}\left(400 \mathrm{MHz},\left(\mathrm{CD}_{3}\right)_{2} \mathrm{CO}\right): \delta=$ $10.08(\mathrm{~s}, 1 \mathrm{H}), 8.83(\mathrm{~s}, 1 \mathrm{H}), 8.54(\mathrm{~s}, 1 \mathrm{H}), 8.30(\mathrm{~d}, J=8.4 \mathrm{~Hz}, 1 \mathrm{H}), 8.07$ $(\mathrm{d}, J=8.4 \mathrm{~Hz}, 1 \mathrm{H}), 7.21(\mathrm{t}, J=7.9 \mathrm{~Hz}, 1 \mathrm{H}), 6.82(\mathrm{~d}, J=7.6 \mathrm{~Hz}, 1 \mathrm{H})$, $6.81(\mathrm{~d}, J=8.2 \mathrm{~Hz}, 1 \mathrm{H}), 2.68(\mathrm{t}, J=8.2 \mathrm{~Hz}, 2 \mathrm{H}), 1.7-1.5(\mathrm{~m}, 2 \mathrm{H}), 1.3-$ $1.2(\mathrm{~m}, 8 \mathrm{H}), 0.82 \mathrm{ppm} \quad(\mathrm{t}, J=6.4 \mathrm{~Hz}, 3 \mathrm{H}) ;{ }^{13} \mathrm{C} \mathrm{NMR} \quad(100 \mathrm{MHz}$, $\left.\left(\mathrm{CD}_{3}\right)_{2} \mathrm{CO}\right): \delta=167.3,154.0,144.0,142.0,136.3,132.7 \quad\left({ }^{2} J_{C-F}=\right.$ $32.1 \mathrm{~Hz}), 130.4,124.6,122.7\left({ }^{1} J_{\mathrm{C}-\mathrm{F}}=273.1 \mathrm{~Hz}\right), 121.9,120.7,116.7$ $\left({ }^{3} J_{\mathrm{C}-\mathrm{F}}=5.6 \mathrm{~Hz}\right), 115.5,113.3,102.8,32.9,31.5,31.3,29.2,28.8,22.4$, 13.4 ppm; IR (NaCl): $\tilde{v}=3600-3000(b r, ~ N-H$ and O-H), $2929(\mathrm{~m}$, $\mathrm{C}-\mathrm{H}), 2855(\mathrm{~m}, \mathrm{C}-\mathrm{H}), 1651(\mathrm{~m}, \mathrm{C}=\mathrm{O}), 1588(\mathrm{~s}, \mathrm{C}=\mathrm{C}), 1535(\mathrm{~s}, \mathrm{C}=\mathrm{C})$, $1426(\mathrm{~s}), 1188 \mathrm{~cm}^{-1}(\mathrm{~s}) ; \mathrm{MS}(\mathrm{ESI}+): \mathrm{m} / \mathrm{z}(\%): 404[\mathrm{M}]^{+}(8), 273(11)$, 220 (15), 219 (100), 218 (21), 186 (37), 134 (20), 108 (21), 107 (24); HRMS (ESI+): $\mathrm{m} / \mathrm{z}[\mathrm{M}]^{+}$calcd for $\mathrm{C}_{22} \mathrm{H}_{23} \mathrm{~F}_{3} \mathrm{~N}_{2} \mathrm{O}_{2}: 404.1712$, found: 404.1731; Anal. calcd for $\mathrm{C}_{22} \mathrm{H}_{23} \mathrm{~F}_{3} \mathrm{~N}_{2} \mathrm{O}_{2}: \mathrm{C}, 65.34 ; \mathrm{H}, 5.73$; found: $\mathrm{C}$, 64.79; $\mathrm{H}, 5.74$.

\section{$\mathrm{N}$-(4-Cyano-3-trifluoromethylphenyl)-2-ethoxy-6-heptylbenz-}

amide (7 c): General procedure for the alkylation of phenols. A solution of $13 \mathrm{c}(0.1 \mathrm{~g}, 0.25 \mathrm{mmol})$ in acetone $(10 \mathrm{~mL})$ was treated sequentially with $\mathrm{K}_{2} \mathrm{CO}_{3}(0.085 \mathrm{~g}, 0.617 \mathrm{mmol})$ and $\mathrm{Et}_{2} \mathrm{SO}_{4}(0.071 \mathrm{~mL}$, $0.54 \mathrm{mmol}$ ). After stirring for $3 \mathrm{~h}$, saturated aq $\mathrm{NH}_{4} \mathrm{Cl}$ was added $(1.5 \mathrm{~mL})$ and the aqueous layer was extracted with $\mathrm{Et}_{2} \mathrm{O}(\times 3)$. The combined organic layers were washed with brine $(\times 2)$, dried $\left(\mathrm{Na}_{2} \mathrm{SO}_{4}\right)$ and the solvent was evaporated. The residue was purified by column chromatography (90:10, hexane/EtOAc) to afford $7 \mathrm{c}$ as a white solid (82 mg, 76\%); mp: $80^{\circ} \mathrm{C}$ (hexane/EtOAc); ${ }^{1} \mathrm{H}$ NMR $\left(400 \mathrm{MHz},\left(\mathrm{CD}_{3}\right)_{2} \mathrm{CO}\right): \delta=10.04(\mathrm{~s}, 1 \mathrm{H}), 8.51(\mathrm{~s}, 1 \mathrm{H}), 8.26(\mathrm{~d}, J=$ $8.5 \mathrm{~Hz}, 1 \mathrm{H}), 8.06(\mathrm{~d}, J=8.5 \mathrm{~Hz}, 1 \mathrm{H}), 7.32(\mathrm{dd}, J=8.3,7.6 \mathrm{~Hz}, 1 \mathrm{H})$, $6.90(\mathrm{~d}, J=8.3 \mathrm{~Hz}, 1 \mathrm{H}), 6.89(\mathrm{~d}, J=7.6 \mathrm{~Hz}, 1 \mathrm{H}), 4.07(\mathrm{q}, J=6.9 \mathrm{~Hz}$, $2 \mathrm{H}), 2.66(\mathrm{t}, J=7.7 \mathrm{~Hz}, 2 \mathrm{H}), 1.7-1.6(\mathrm{~m}, 2 \mathrm{H}), 1.4-1.2(\mathrm{~m}, 11 \mathrm{H})$, $0.81 \mathrm{ppm} \quad(\mathrm{t}, J=6.8 \mathrm{~Hz}, 3 \mathrm{H}) ;{ }^{13} \mathrm{C}$ NMR $\left(100 \mathrm{MHz},\left(\mathrm{CD}_{3}\right)_{2} \mathrm{CO}\right): \delta=$ $168.9,157.6,145.8,143.8,138.2,134.7\left({ }^{2} J_{\mathrm{C}-\mathrm{F}}=31.8 \mathrm{~Hz}\right), 132.3,128.2$, $124.7\left({ }^{1} J_{\mathrm{C}-\mathrm{F}}=272.7 \mathrm{~Hz}\right), 123.6,123.5,118.5\left({ }^{3} J_{\mathrm{C}-\mathrm{F}}=5.7 \mathrm{~Hz}\right), 117.4$, $111.5,104.8,65.9,34.7$ (2C), 33.4, 33.1, 31.4, 24.2, 16.0, 15.3 ppm; IR $(\mathrm{NaCl}): \tilde{v}=3300-3100(\mathrm{br}, \mathrm{N}-\mathrm{H}), 2928(\mathrm{~s}, \mathrm{C}-\mathrm{H}), 2856(\mathrm{~m}, \mathrm{C}-\mathrm{H}), 1668$ $(\mathrm{m}, \mathrm{C}=\mathrm{O}), 1587(\mathrm{~s}, \mathrm{C}=\mathrm{C}), 1528(\mathrm{~s}, \mathrm{C}=\mathrm{C}), 1326(\mathrm{~s}), 1269(\mathrm{~s}), 1179(\mathrm{~s})$, $1140 \mathrm{~cm}^{-1}(\mathrm{~s})$; MS (ESI+): $\mathrm{m} / z(\%): 432[M]^{+}(3), 248(60), 247(100)$, 147 (19), 145 (16), 135 (19), 133 (15), 107 (14), 105 (11); HRMS $(\mathrm{ESI}+): \mathrm{m} / \mathrm{z}[\mathrm{M}]^{+}$calcd for $\mathrm{C}_{24} \mathrm{H}_{27} \mathrm{~F}_{3} \mathrm{~N}_{2} \mathrm{O}_{2}: 432.2025$, found: 432.2024; Anal. calcd for $\mathrm{C}_{24} \mathrm{H}_{37} \mathrm{~F}_{3} \mathrm{~N}_{2} \mathrm{O}_{2}$ : C, 66.65; H, 6.29; found: $\mathrm{C}$, $66.81 ; \mathrm{H}, 6.66$.

2,2-Dimethyl-5-hexyl-4H-1,3-benzodioxin-4-one (11 d): Following the general procedure described for the Suzuki cross coupling (Method A), the reaction of $9(0.25 \mathrm{~g}, 0.07 \mathrm{mmol}), 10 \mathrm{~d}(0.06$, $0.65 \mathrm{mmol}), 9-\mathrm{BBN}(1.3 \mathrm{~mL}, 0.65 \mathrm{mmol}), \mathrm{MeONa}(0.04 \mathrm{~g}, 0.65 \mathrm{mmol})$, $\mathrm{PdCl}_{2}$ (dppf) $(6 \mathrm{mg}, 0.02 \mathrm{mmol})$ and $\mathrm{KBr}(0.09 \mathrm{~g}, 0.73 \mathrm{mmol})$ in THF $(5.4 \mathrm{~mL})$ afforded, after purification by column chromatography (90:10, hexane/EtOAc), $11 \mathrm{~d}$ as a colourless oil (71 mg, $41 \%)$; ${ }^{1} \mathrm{H}$ NMR $\left(400 \mathrm{MHz}, \mathrm{CDCl}_{3}\right): \delta=7.40(\mathrm{t}, J=7.9 \mathrm{~Hz}, 1 \mathrm{H}), 6.94(\mathrm{~d}, J=$ $7.6 \mathrm{~Hz}, 1 \mathrm{H}), 6.80(\mathrm{~d}, J=8.2 \mathrm{~Hz}, 1 \mathrm{H}), 3.09(\mathrm{t}, J=7.9 \mathrm{~Hz}, 2 \mathrm{H}), 1.70(\mathrm{~s}$, $\left.6 \mathrm{H}, 2 \mathrm{CH}_{3}\right), 1.6-1.5(\mathrm{~m}, 2 \mathrm{H}), 1.4-1.3(\mathrm{~m}, 6 \mathrm{H}), 0.89 \mathrm{ppm}(\mathrm{t}, J=6.2 \mathrm{~Hz}$, $3 \mathrm{H}) ;{ }^{13} \mathrm{C}$ NMR $\left(100 \mathrm{MHz}, \mathrm{CDCl}_{3}\right): \delta=160.2,157.1,148.5,135.0$, 125.0, 115.0, 112.0, 104.9, 34.3, 31.6, 31.1, 29.3, 25.6 (2C), 22.6, 14.0 ppm; IR (NaCl): $\tilde{v}=2998(\mathrm{w}, \mathrm{C}-\mathrm{H}), 2925(\mathrm{~s}, \mathrm{C}-\mathrm{H}), 2855(\mathrm{~m}, \mathrm{C}-$ H), $1739(\mathrm{~s}, \mathrm{C}=0), 1605(\mathrm{~m}, \mathrm{C}=\mathrm{C}), 1582(\mathrm{~m}, \mathrm{C}=\mathrm{C}), 1312(\mathrm{~m}), 1213$ $(\mathrm{m}), 1042 \mathrm{~cm}^{-1}(\mathrm{~m}) ; \mathrm{MS}(\mathrm{ESI}+): \mathrm{m} / \mathrm{z}(\%): 262[M]^{+}(8), 204(100)$, 162 (32), 147 (22), 134 (57), 105 (25); HRMS (ESI+): $\mathrm{m} / z[\mathrm{~m}]^{+}$calcd for $\mathrm{C}_{16} \mathrm{H}_{22} \mathrm{O}_{3}: 262.1569$, found: 262.1572 . 
$\mathrm{N}$-(4-Cyano-3-trifluoromethylphenyl)-6-hexyl-2-hydroxybenzamide (13d): Following the general procedure described for amide formation, the reaction of $11 \mathrm{~d}(0.06 \mathrm{~g}, 0.23 \mathrm{mmol}), 12$ $(0.21 \mathrm{~g}, 1.15 \mathrm{mmol}), n$ BuLi $(0.82 \mathrm{~mL}, 1.40 \mathrm{M}$ in hexane, $1.15 \mathrm{mmol})$ and DMPU $(0.2 \mathrm{~mL}, 1.68 \mathrm{mmol})$ in THF $(8.8 \mathrm{~mL})$ afforded, after purification by column chromatography ( $80: 20$, hexane/EtOAc), $13 \mathbf{d}$ as a white solid $(58 \mathrm{mg}, 65 \%) ; \mathrm{mp}: 161^{\circ} \mathrm{C}$ (hexane/acetone); ${ }^{1} \mathrm{H}$ NMR $\left(400 \mathrm{MHz},\left(\mathrm{CD}_{3}\right)_{2} \mathrm{CO}\right): \delta=10.07(\mathrm{br}, 1 \mathrm{H}), 8.54(\mathrm{~s}, 1 \mathrm{H}), 8.29$ $(\mathrm{d}, J=8.4 \mathrm{~Hz}, 1 \mathrm{H}), 8.07(\mathrm{~d}, J=8.5 \mathrm{~Hz}, 1 \mathrm{H}), 7.21(\mathrm{t}, J=7.9 \mathrm{~Hz}, 1 \mathrm{H})$, $6.82(\mathrm{~d}, J=7.7 \mathrm{~Hz}, 1 \mathrm{H}), 6.81(\mathrm{~d}, J=8.1 \mathrm{~Hz}, 1 \mathrm{H}), 2.85(\mathrm{br}, 1 \mathrm{H}), 2.68(\mathrm{t}$, $J=7.9 \mathrm{~Hz}, 2 \mathrm{H}), 1.7-1.6(\mathrm{~m}, 2 \mathrm{H}), 1.4-1.3(\mathrm{~m}, 2 \mathrm{H}), 1.3-1.2(\mathrm{~m}, 4 \mathrm{H})$, $0.82 \mathrm{ppm} \quad(\mathrm{t}, J=6.7 \mathrm{~Hz}, 3 \mathrm{H}) ;{ }^{13} \mathrm{C}$ NMR $\left(100 \mathrm{MHz},\left(\mathrm{CD}_{3}\right)_{2} \mathrm{CO}\right): \delta=$ $167.2,154.0,143.9,142.0,136.3,132.7\left({ }^{2} J_{C-F}=31.3 \mathrm{~Hz}\right), 130.4,124.5$, $123.0\left({ }^{1} J_{C-F}=273.0 \mathrm{~Hz}\right), 121.9,120.7,116.7\left({ }^{3} J_{\mathrm{C}-\mathrm{F}}=5.7 \mathrm{~Hz}\right), \quad 115.5$, $113.3,102.9,32.9,31.4,31.2,28.9,22.2,13.3 \mathrm{ppm} ; \mathrm{IR}(\mathrm{NaCl}): \tilde{v}=$ 3600-3000 (br, N-H and O-H), $3020(\mathrm{~m}, \mathrm{C}-\mathrm{H}), 2931(\mathrm{~m}, \mathrm{C}-\mathrm{H})$, $2857(\mathrm{w}, \mathrm{C}-\mathrm{H}), 1654(\mathrm{~m}, \mathrm{C}=\mathrm{O}), 1588(\mathrm{~s}, \mathrm{C}=\mathrm{C}), 1534(\mathrm{~s}, \mathrm{C}=\mathrm{C}), 1426$ (s), 1331 (s), $1217 \mathrm{~cm}^{-1}(\mathrm{~s})$; MS (ESI+): $\mathrm{m} / \mathrm{z}(\%): 390[M]^{+}$(7), 212 (29), 205 (100), 186 (54), 108 (31), 107 (34), 77 (18); HRMS (ESI+): $\mathrm{m} / \mathrm{z}[\mathrm{M}]^{+}$calcd for $\mathrm{C}_{21} \mathrm{H}_{21} \mathrm{~F}_{3} \mathrm{~N}_{2} \mathrm{O}_{2}: 390.1555$, found: 390.1552 .

\section{$\mathrm{N}$-(4-Cyano-3-trifluoromethylphenyl)-2-ethoxy-6-hexylbenz-}

amide (7d): Following the general procedure described for the alkylation of phenols, the reaction of $13 \mathrm{~d}(0.03 \mathrm{~g}, 0.08 \mathrm{mmol}), \mathrm{Et}_{2} \mathrm{SO}_{4}$ $(0.02 \mathrm{~mL}, 0.17 \mathrm{mmol})$ and $\mathrm{K}_{2} \mathrm{CO}_{3}(0.03 \mathrm{~g}, 0.19 \mathrm{mmol})$ in acetone (3.2 $\mathrm{mL}$ ) afforded, after purification by column chromatography (90:10, hexane/EtOAc), $7 \mathrm{~d}$ as a white solid $(15 \mathrm{mg}, 46 \%) ; \mathrm{mp}$ : $109^{\circ} \mathrm{C}$ (hexane/EtOAc); ${ }^{1} \mathrm{H}$ NMR $\left(400 \mathrm{MHz}, \mathrm{CDCl}_{3}\right): \delta=8.1-8.0(\mathrm{~m}$, $3 \mathrm{H}), 7.81(\mathrm{~d}, J=8.2 \mathrm{~Hz}, 1 \mathrm{H}), 7.31(\mathrm{t}, J=8.0 \mathrm{~Hz}, 1 \mathrm{H}), 6.89(\mathrm{~d}, J=$ $7.7 \mathrm{~Hz}, 1 \mathrm{H}), 6.80(\mathrm{~d}, J=8.3 \mathrm{~Hz}, 1 \mathrm{H}), 4.08(\mathrm{q}, J=6.9 \mathrm{~Hz}, 2 \mathrm{H}), 2.71(\mathrm{t}$, $J=7.7 \mathrm{~Hz}, 2 \mathrm{H}), 1.6-1.5(\mathrm{~m}, 2 \mathrm{H}), 1.4-1.2(\mathrm{~m}, 9 \mathrm{H}), 0.85 \mathrm{ppm}(\mathrm{t}, J=$ $6.5 \mathrm{~Hz}, 3 \mathrm{H}) ;{ }^{13} \mathrm{CNMR}\left(100 \mathrm{MHz}, \mathrm{CDCl}_{3}\right): \delta=166.5,155.5,143.6$, $142.4,136.0,134.1 \quad\left({ }^{2} J_{C-F}=33.0 \mathrm{~Hz}\right), 131.2,124.6,122.6,122.2$ $\left({ }^{1} J_{\mathrm{C}-\mathrm{F}}=274.0 \mathrm{~Hz}\right), 121.7,117.0\left({ }^{3} J_{\mathrm{C}-\mathrm{F}}=4.8 \mathrm{~Hz}\right), 115.6,109.7,104.1$, $64.5,33.4,31.6,31.5,29.2,22.5,14.8,14.0$ ppm; IR ( NaCl): $\tilde{v}=3500$ 3100 (br, N-H), $2929(\mathrm{~s}, \mathrm{C}-\mathrm{H}), 2857(\mathrm{~m}, \mathrm{C}-\mathrm{H}), 1668(\mathrm{~m}, \mathrm{C}=\mathrm{O}), 1587$ $(\mathrm{s}, \mathrm{C}=\mathrm{C}), 1528(\mathrm{~s}, \mathrm{C}=\mathrm{C}), 1327(\mathrm{~s}), 1179(\mathrm{~s}), 1140 \mathrm{~cm}^{-1}(\mathrm{~s})$; MS (ESI +): $\mathrm{m} / \mathrm{z}(\%): 418\left[\mathrm{M}^{+}\right.$(6), 234 (99), 233 (100), 205 (22), 147 (47), 145 (63), 135 (58), 134 (29), 133 (52), 107 (52), 105 (35), 91 (29), 77 (28); HRMS (ESI +$): m / z[M]^{+}$calcd for $\mathrm{C}_{23} \mathrm{H}_{25} \mathrm{~F}_{3} \mathrm{~N}_{2} \mathrm{O}_{2}: 418.1868$, found: 418.1870; Anal. calcd for $\mathrm{C}_{23} \mathrm{H}_{25} \mathrm{~F}_{3} \mathrm{~N}_{2} \mathrm{O}_{2}$ : $\mathrm{C}, 66.02 ; \mathrm{H}, 6.02$; found: $\mathrm{C}$, $66.21 ; \mathrm{H}, 6.07$.

\section{2,2-Dimethyl-5-(tert-butyldimethylsilyloxypent-1-yl)-4H-1,3-ben-} zodioxin-4-one (11 e): Following the general procedure described for the Suzuki cross coupling (Method A), the reaction of $9(0.25 \mathrm{~g}$, $0.07 \mathrm{mmol}), 10 \mathrm{e}(0.13 \mathrm{~g}, 0.65 \mathrm{mmol}), 9-\mathrm{BBN}(1.3 \mathrm{~mL}, 0.5 \mathrm{M}$ in THF, $0.65 \mathrm{mmol}), \mathrm{MeONa}(0.04 \mathrm{~g}, 0.65 \mathrm{mmol}), \mathrm{PdCl}_{2}(\mathrm{dppf}) \quad(6 \mathrm{mg}$ $0.02 \mathrm{mmol})$ and $\mathrm{KBr}(0.09 \mathrm{~g}, 0.73 \mathrm{mmol})$ in THF $(5.4 \mathrm{~mL})$ afforded, after purification by column chromatography (90:10, hexane/ EtOAc), $11 \mathrm{e}$ as a colourless oil $(80 \mathrm{mg}, 32 \%) ;{ }^{1} \mathrm{H}$ NMR $(400 \mathrm{MHz}$ $\left.\mathrm{CDCl}_{3}\right): \delta=7.40(\mathrm{t}, J=7.9 \mathrm{~Hz}, 1 \mathrm{H}), 6.93(\mathrm{~d}, J=7.6 \mathrm{~Hz}, 1 \mathrm{H}), 6.81(\mathrm{~d}$, $J=8.2 \mathrm{~Hz}, 1 \mathrm{H}), 3.61(\mathrm{t}, J=6.5 \mathrm{~Hz}, 2 \mathrm{H}), 3.09(\mathrm{t}, J=7.7 \mathrm{~Hz}, 2 \mathrm{H}), 1.70$ $\left(\mathrm{s}, 6 \mathrm{H}, 2 \mathrm{CH}_{3}\right), 1.6-1.4(\mathrm{~m}, 6 \mathrm{H}), 0.89\left(\mathrm{~s}, 9 \mathrm{H}, \mathrm{SiC}\left(\mathrm{CH}_{3}\right)_{3}, 0.04 \mathrm{ppm}(\mathrm{s}\right.$, $\left.6 \mathrm{H}, 2 \mathrm{SiCH}_{3}\right) ;{ }^{13} \mathrm{CNMR}\left(100 \mathrm{MHz}, \mathrm{CDCl}_{3}\right): \delta=160.2,157.1,148.3$, $135.1,125.1,115.1,112.0,104.9,63.1,34.3,32.7,30.9,26.0$ (3C), 25.8, $25.6(2 \mathrm{C}), 18.4,-5.2 \mathrm{ppm}(2 \mathrm{C})$; IR $(\mathrm{NaCl}): \tilde{v}=2929(\mathrm{~m}, \mathrm{C}-\mathrm{H})$, $2857(\mathrm{~m}, \mathrm{C}-\mathrm{H}), 1740(\mathrm{~s}, \mathrm{C}=\mathrm{O}), 1606(\mathrm{~m}, \mathrm{C}=\mathrm{C}), 1582(\mathrm{~s}, \mathrm{C}=\mathrm{C})$, $1476 \mathrm{~cm}^{-1}(\mathrm{~s}, \mathrm{C}=\mathrm{C}) ; \mathrm{MS}(\mathrm{ESI}+) 401[\mathrm{M+Na}]^{+}(100), 379[\mathrm{M+H}]^{+}$ (76), 287 (9), 201 (20); HRMS (ESI+): $\mathrm{m} / \mathrm{z}[\mathrm{M+H}]^{+}$calcd for $\mathrm{C}_{21} \mathrm{H}_{35} \mathrm{O}_{4} \mathrm{Si}: 379.2299$, found: 379.2300 .

$\mathrm{N}$-(4-Cyano-3-trifluoromethylphenyl)-6-(5-tert-butyldimethylsilyloxypent-1-yl)-2-hydroxybenzamide (13e): Following the general procedure described for amide formation, the reaction of $11 \mathrm{e}$
$(0.08 \mathrm{~g}, 0.21 \mathrm{mmol}), 12(0.20 \mathrm{~g}, 1.05 \mathrm{mmol}), n B u L i(0.75 \mathrm{~mL}, 1.40 \mathrm{M}$ in hexane, $1.05 \mathrm{mmol})$ and DMPU $(0.19 \mathrm{~mL}, 1.54 \mathrm{mmol})$ in THF $(8.1 \mathrm{~mL})$ afforded, after purification by column chromatography (80:20, hexane/EtOAc), $13 \mathrm{e}$ as a colourless oil (37 mg, $35 \%)$; ${ }^{1} \mathrm{H}$ NMR $\left(400 \mathrm{MHz},\left(\mathrm{CD}_{3}\right)_{2} \mathrm{CO}\right): \delta=10.00(\mathrm{br}, 1 \mathrm{H}), 8.86(\mathrm{~s}, 1 \mathrm{H}), 8.54(\mathrm{~s}$, $1 \mathrm{H}), 8.30(\mathrm{~d}, J=8.2 \mathrm{~Hz}, 1 \mathrm{H}), 8.07(\mathrm{~d}, J=8.3 \mathrm{~Hz}, 1 \mathrm{H}), 7.21(\mathrm{t}, J=$ $8.0 \mathrm{~Hz}, 1 \mathrm{H}), 6.82(\mathrm{~d}, J=7.6 \mathrm{~Hz}, 1 \mathrm{H}), 6.81(\mathrm{~d}, J=8.2 \mathrm{~Hz}, 1 \mathrm{H}), 3.59(\mathrm{t}$, $J=6.2 \mathrm{~Hz}, 2 \mathrm{H}), 2.69(\mathrm{t}, J=7.9 \mathrm{~Hz}, 2 \mathrm{H}), 1.7-1.4(\mathrm{~m}, 6 \mathrm{H}), 0.86(\mathrm{~s}, 9 \mathrm{H}$, $\left.\mathrm{SiC}\left(\mathrm{CH}_{3}\right)_{3}\right), 0.01 \mathrm{ppm}\left(\mathrm{s}, 6 \mathrm{H}, 2 \mathrm{SiCH}_{3}\right) ;{ }^{13} \mathrm{C} \mathrm{NMR}\left(100 \mathrm{MHz},\left(\mathrm{CD}_{3}\right)_{2} \mathrm{CO}\right)$ : $\delta=167.2,154.1,144.0,141.9,136.3,132.8\left({ }^{2} J_{C-F}=32.1 \mathrm{~Hz}\right), 130.4$, $124.5,122.8\left({ }^{1} J_{\mathrm{C}-\mathrm{F}}=273.0 \mathrm{~Hz}\right), 121.9,120.7,116.7\left({ }^{3} J_{\mathrm{C}-\mathrm{F}}=4.9 \mathrm{~Hz}\right)$, $115.5,113.3,102.9,62.5,33.0,32.4,31.1,25.5,25.4$ (3C), 17.9, $-6.1 \mathrm{ppm}(2 \mathrm{C}) ; \mathrm{IR}(\mathrm{NaCl}): \tilde{\mathrm{v}}=3500-3000(\mathrm{br}, \mathrm{N}-\mathrm{H}$ and O-H), 2931 (s, C-H), $2858(\mathrm{~m}, \mathrm{C}-\mathrm{H}), 1656(\mathrm{~m}, \mathrm{C}=\mathrm{O}), 1588(\mathrm{~s}, \mathrm{C}=\mathrm{C}), 1533(\mathrm{~s}, \mathrm{C}=$ C), $1426(\mathrm{~s}), 1330 \mathrm{~cm}^{-1}(\mathrm{~s})$; MS (ESI+): $507[\mathrm{M+H}]^{+}(24), 371(56)$, 197 (100); HRMS (ESI+): $\mathrm{m} / \mathrm{z}[\mathrm{M}+\mathrm{H}]^{+}$calcd for $\mathrm{C}_{26} \mathrm{H}_{34} \mathrm{~F}_{3} \mathrm{~N}_{2} \mathrm{O}_{3} \mathrm{Si}$ : 507.2285, found: 507.2298.

$\mathrm{N}$-(4-Cyano-3-trifluoromethylphenyl)-2-ethoxy-6-(5-hydroxypent1-yl)benzamide (7e): Following the general procedure described for the alkylation of phenols, the reaction of $13 \mathrm{e}(0.03 \mathrm{~g}$, $0.05 \mathrm{mmol}), \mathrm{Et}_{2} \mathrm{SO}_{4}(0.02 \mathrm{~mL}, 0.12 \mathrm{mmol}), \mathrm{K}_{2} \mathrm{CO}_{3}(0.02 \mathrm{~g}, 0.13 \mathrm{mmol})$ in acetone $(2.1 \mathrm{~mL})$ afforded, after purification by column chromatography (90:10, hexane/EtOAc), a colourless oil (16 mg) that was used in the next step without further purification. General procedure for the deprotection of silyl ethers. A solution of the residue obtained above $(0.02 \mathrm{~g}, 0.03 \mathrm{mmol})$ in THF $(0.5 \mathrm{~mL})$ at $0{ }^{\circ} \mathrm{C}$ was treated with TBAF $(0.05 \mathrm{~mL}, 1 \mathrm{M}$ in THF, $0.055 \mathrm{mmol})$ and stirred at RT for $5 \mathrm{~h}$. The mixture was diluted with EtOAc and washed with saturated aq $\mathrm{NaHCO}_{3}(\times 3)$. The aqueous layer was extracted with EtOAc $(\times 3)$ and the combined organic layers were washed with brine $(\times 3)$, dried $\left(\mathrm{Na}_{2} \mathrm{SO}_{4}\right)$ and the solvent was evaporated. The residue was purified by column chromatography (50:50, hexane/ EtOAc) to afford $7 \mathrm{e}$ as a colourless oil ( $8 \mathrm{mg}, 61 \%$ combined yield); ${ }^{1} \mathrm{H}$ NMR $\left(400 \mathrm{MHz}, \mathrm{CDCl}_{3}\right): \delta=8.27(\mathrm{~s}, 1 \mathrm{H}), 8.06(\mathrm{~s}, 1 \mathrm{H}), 8.04$ $(\mathrm{d}, J=8.1 \mathrm{~Hz}, 1 \mathrm{H}), 7.82(\mathrm{~d}, J=8.2 \mathrm{~Hz}, 1 \mathrm{H}), 7.32(\mathrm{t}, J=8.0 \mathrm{~Hz}, 1 \mathrm{H})$, $6.90(\mathrm{~d}, J=7.7 \mathrm{~Hz}, 1 \mathrm{H}), 6.81(\mathrm{~d}, J=8.3 \mathrm{~Hz}, 1 \mathrm{H}), 4.09(\mathrm{q}, J=6.6 \mathrm{~Hz}$, $2 \mathrm{H}), 3.60(\mathrm{t}, J=6.3 \mathrm{~Hz}, 2 \mathrm{H}), 2.74(\mathrm{t}, J=7.6 \mathrm{~Hz}, 2 \mathrm{H}), 1.7-1.4 \mathrm{ppm}(\mathrm{m}$, $9 \mathrm{H}) ;{ }^{13} \mathrm{C} \mathrm{NMR}\left(100 \mathrm{MHz}, \mathrm{CDCl}_{3}\right): \delta=166.6,155.6,143.0,142.4$, 136.0, $134.1 \quad\left({ }^{2} J_{\mathrm{C}-\mathrm{F}}=33.0 \mathrm{~Hz}\right), 131.2,124.8,122.5,122.2 \quad\left({ }^{1} J_{\mathrm{C}-\mathrm{F}}=\right.$ $273.1 \mathrm{~Hz}), 121.7,117.1\left({ }^{3} J_{\mathrm{C}-\mathrm{F}}=4.8 \mathrm{~Hz}\right), 115.6,109.8,104.1,64.5,62.7$, $33.2,32.3,30.9,25.4,14.8 \mathrm{ppm}$; IR $(\mathrm{NaCl}): \tilde{\mathrm{v}}=3500-3000(\mathrm{br}, \mathrm{N}-\mathrm{H}$ and O-H), $2932(\mathrm{~s}, \mathrm{C}-\mathrm{H}), 2859(\mathrm{~m}, \mathrm{C}-\mathrm{H}), 1679(\mathrm{~m}, \mathrm{C}=\mathrm{O}), 1588(\mathrm{~s}$, $\mathrm{C}=\mathrm{C}), 1529(\mathrm{~s}, \mathrm{C}=\mathrm{C}), 1327(\mathrm{~s}), 1138 \mathrm{~cm}^{-1}(\mathrm{~s}) ; \mathrm{MS}(\mathrm{ESI}+): 443$ $[M+\mathrm{Na}]^{+}(33), 421[M+\mathrm{H}]^{+}(100) ; \mathrm{HRMS}(\mathrm{ESI}+): \mathrm{m} / z[\mathrm{M}+\mathrm{H}]^{+}$calcd for $\mathrm{C}_{22} \mathrm{H}_{24} \mathrm{~F}_{3} \mathrm{~N}_{2} \mathrm{O}_{3}: 421.1734$, found: 421.1736 .

\section{2,2-Dimethyl-5-(tert-butyldimethylsilyloxybut-1-yl)-4H-1,3-ben-} zodioxin-4-one $(\mathbf{1 1} \mathrm{f})$ : Following the general procedure described for the Suzuki cross coupling (Method A), the reaction of $9(0.25 \mathrm{~g}$, $0.07 \mathrm{mmol}), 10 \mathrm{f}(0.12 \mathrm{~g}, 0.65 \mathrm{mmol}), 9-\mathrm{BBN}(1.3 \mathrm{~mL}, 0.5 \mathrm{M}$ in THF, $0.65 \mathrm{mmol}), \mathrm{MeONa}(0.04 \mathrm{~g}, 0.65 \mathrm{mmol}), \mathrm{PdCl}_{2}(\mathrm{dppf})(6 \mathrm{mg}$, $0.02 \mathrm{mmol})$ and $\mathrm{KBr}(0.09 \mathrm{~g}, 0.73 \mathrm{mmol})$ in THF $(5.4 \mathrm{~mL})$ afforded, after purification by column chromatography (90:10, hexane/ EtOAc), $11 \mathrm{f}$ as a colourless oil (160 mg, $66 \%) ;{ }^{1} \mathrm{H} \mathrm{NMR}(400 \mathrm{MHz}$, $\left.\mathrm{CDCl}_{3}\right): \delta=7.39(\mathrm{t}, J=7.9 \mathrm{~Hz}, 1 \mathrm{H}), 6.93(\mathrm{~d}, J=7.6 \mathrm{~Hz}, 1 \mathrm{H}), 6.80(\mathrm{~d}$, $J=8.2 \mathrm{~Hz}, 1 \mathrm{H}), 3.63(\mathrm{t}, J=5.8 \mathrm{~Hz}, 2 \mathrm{H}), 3.11(\mathrm{t}, J=7.0 \mathrm{~Hz}, 2 \mathrm{H}), 1.69$ $\left(\mathrm{s}, 6 \mathrm{H}, 2 \mathrm{CH}_{3}\right), 1.7-1.6(\mathrm{~m}, 4 \mathrm{H}), 0.88\left(\mathrm{~s}, 9 \mathrm{H}, \mathrm{SiC}\left(\mathrm{CH}_{3}\right)_{3}\right), 0.03 \mathrm{ppm}(\mathrm{s}$, $\left.6 \mathrm{H}, 2 \mathrm{SiCH}_{3}\right) ;{ }^{13} \mathrm{CNMR}\left(100 \mathrm{MHz}, \mathrm{CDCl}_{3}\right): \delta=160.2,157.1,148.1$, $135.1,125.1,115.2,112.1,104.9,63.1,34.0,32.7,27.3,26.0$ (3C), 25.6 (2C), 18.3, -5.2 ppm (2C); IR ( NaCl): $\tilde{v}=2929(\mathrm{~s}, \mathrm{C}-\mathrm{H}), 2857$ $(\mathrm{m}, \mathrm{C}-\mathrm{H}), 1739(\mathrm{~s}, \mathrm{C}=\mathrm{O}), 1605(\mathrm{~m}, \mathrm{C}=\mathrm{C}), 1582(\mathrm{~m}, \mathrm{C}=\mathrm{C}), 1312(\mathrm{~m})$, $1217 \mathrm{~cm}^{-1}(\mathrm{~m})$; $\mathrm{MS}(\mathrm{ESI}+)$ : $387[\mathrm{M}+\mathrm{Na}]^{+}(42), 365[M+\mathrm{H}]^{+}(100)$; 
HRMS (ESI+): $m / z[M+H]^{+}$calcd for $\mathrm{C}_{20} \mathrm{H}_{33} \mathrm{O}_{4} \mathrm{Si}: 365.2143$, found: 365.2142

\section{$\mathrm{N}$-(4-Cyano-3-(trifluoromethyl)phenyl)-6-(4-tert-butyldimethylsi-} lyloxybut-1-yl)-2-hydroxybenzamide (13 f): Following the general procedure described for amide formation, the reaction of $\mathbf{1 1} \mathrm{f}$ $(0.16 \mathrm{~g}, 0.44 \mathrm{mmol}), 12(0.41 \mathrm{~g}, 2.20 \mathrm{mmol}), \mathrm{nBuLi}(1.57 \mathrm{~mL}, 1.40 \mathrm{M}$ in hexane, $2.20 \mathrm{mmol})$ and DMPU $(0.39 \mathrm{~mL}, 3.20 \mathrm{mmol})$ in THF $(17 \mathrm{~mL})$ afforded, after purification by column chromatography $(80: 20$, hexane/EtOAc), $13 \mathrm{f}$ as a colourless oil $(109 \mathrm{mg}, 50 \%)$; ${ }^{1} \mathrm{H}$ NMR $\left(400 \mathrm{MHz},\left(\mathrm{CD}_{3}\right)_{2} \mathrm{CO}\right): \delta=10.06(\mathrm{br}, 1 \mathrm{H}), 8.54(\mathrm{~s}, 1 \mathrm{H}), 8.30$ (d, $J=8.5 \mathrm{~Hz}, 1 \mathrm{H}), 8.06(\mathrm{~d}, J=8.6 \mathrm{~Hz}, 1 \mathrm{H}), 7.21(\mathrm{t}, J=7.9 \mathrm{~Hz}, 1 \mathrm{H})$, $6.82(\mathrm{~d}, J=7.6 \mathrm{~Hz}, 1 \mathrm{H}), 6.81(\mathrm{~d}, J=7.6 \mathrm{~Hz}, 1 \mathrm{H}), 3.61(\mathrm{t}, J=6.3 \mathrm{~Hz}$, $2 \mathrm{H}), 2.71(\mathrm{t}, J=7.4 \mathrm{~Hz}, 2 \mathrm{H}), 1.7-1.4(\mathrm{~m}, 4 \mathrm{H}), 0.84\left(\mathrm{~s}, 9 \mathrm{H}, \mathrm{SiC}\left(\mathrm{CH}_{3}\right)_{3}\right)$, $-0.01 \mathrm{ppm}\left(\mathrm{s}, 6 \mathrm{H}, 2 \mathrm{SiCH}_{3}\right) ;{ }^{13} \mathrm{C}$ NMR $\left(100 \mathrm{MHz},\left(\mathrm{CD}_{3}\right)_{2} \mathrm{CO}\right): \delta=167.3$, 154.1, 144.0, 141.9, 136.3, $132.8\left({ }^{2} J_{C-F}=32.1 \mathrm{~Hz}\right), 130.4,124.6,122.8$ $\left({ }^{1} J_{\mathrm{C}-\mathrm{F}}=273.0 \mathrm{~Hz}\right), 121.9,120.6,116.7\left({ }^{3} J_{\mathrm{C}-\mathrm{F}}=4.1 \mathrm{~Hz}\right), 115.6,113.4$, $102.8,62.5,32.7,32.5,27.6,25.4$ (3C), 17.9, $-6.1 \mathrm{ppm}(2 \mathrm{C})$; IR $(\mathrm{NaCl}): \tilde{v}=3500-3000(\mathrm{br}, \mathrm{N}-\mathrm{H}$ and O-H), $2953(\mathrm{~s}, \mathrm{C}-\mathrm{H}), 2931(\mathrm{~s}$, $\mathrm{C}-\mathrm{H}), 2857(\mathrm{~m}, \mathrm{C}-\mathrm{H}), 1656(\mathrm{~m}, \mathrm{C}=\mathrm{O}), 1588(\mathrm{~s}, \mathrm{C}=\mathrm{C}), 1533(\mathrm{~s}, \mathrm{C}=\mathrm{C})$, $1426(\mathrm{~s}), 1329(\mathrm{~s}), 1187 \mathrm{~cm}^{-1}(\mathrm{~m}) ; \mathrm{MS}(\mathrm{ESI}+): 515[\mathrm{M}+\mathrm{Na}]^{+}$(38), $493\left[[\mathrm{M}+\mathrm{H}]^{+}(100) ; \mathrm{HRMS} \quad(\mathrm{ESI}+): \mathrm{m} / \mathrm{z} \quad[\mathrm{M}+\mathrm{H}]^{+}\right.$calcd for $\mathrm{C}_{25} \mathrm{H}_{32} \mathrm{~F}_{3} \mathrm{~N}_{2} \mathrm{O}_{3} \mathrm{Si}$ : 493.2129, found: 493.2128.

\section{$\mathrm{N}$-(4-Cyano-3-trifluoromethylphenyl)-2-ethoxy-6-(4-hydroxybut-} 1-yl)benzamide (7f): Following the general procedure described for the alkylation of phenols, the reaction of $13 \mathrm{f}(0.08 \mathrm{~g}$, $0.16 \mathrm{mmol}), \mathrm{Et}_{2} \mathrm{SO}_{4}(0.05 \mathrm{~mL}, 0.36 \mathrm{mmol}), \mathrm{K}_{2} \mathrm{CO}_{3}(0.06 \mathrm{~g}, 0.41 \mathrm{mmol})$ in acetone $(6.5 \mathrm{~mL})$ afforded, after purification by column chromatography (80:20, hexane/EtOAc), a colourless oil $(67 \mathrm{mg})$ that was used in the next step without further purification. Following the general procedure described for the deprotection of silyl ethers, the reaction of the residue obtained above $(67 \mathrm{mg}, 0.129 \mathrm{mmol})$ and TBAF $(0.19 \mathrm{~mL}, 1 \mathrm{M}$ in THF, $0.19 \mathrm{mmol})$ in THF $(2.2 \mathrm{~mL})$ afforded, after purification by column chromatography $(60: 40$, hexane/ EtOAc), $7 \mathrm{f}$ as a colourless oil $(27 \mathrm{mg}, 51 \%) ;{ }^{1} \mathrm{H}$ NMR $(400 \mathrm{MHz}$, $\left.\left(\mathrm{CD}_{3}\right)_{2} \mathrm{CO}\right): \delta=10.07(\mathrm{br}, 1 \mathrm{H}), 8.51(\mathrm{~s}, 1 \mathrm{H}), 8.26(\mathrm{~d}, J=7.1 \mathrm{~Hz}, 1 \mathrm{H})$, $8.07(\mathrm{~d}, J=8.5 \mathrm{~Hz}, 1 \mathrm{H}), 7.33(\mathrm{t}, J=8.0 \mathrm{~Hz}, 1 \mathrm{H}), 6.92(\mathrm{~d}, J=7.4 \mathrm{~Hz}$, $2 \mathrm{H}), 4.08(\mathrm{q}, J=7.0 \mathrm{~Hz}, 2 \mathrm{H}), 3.50(\mathrm{t}, J=6.0 \mathrm{~Hz}, 2 \mathrm{H}), 3.39(\mathrm{t}, J=$ $5.2 \mathrm{~Hz}, 1 \mathrm{H}), 2.70(\mathrm{t}, J=7.8 \mathrm{~Hz}, 2 \mathrm{H}), 1.7-1.5(\mathrm{~m}, 4 \mathrm{H}), 1.30 \mathrm{ppm}(\mathrm{t}, J=$ $6.9 \mathrm{~Hz}, 3 \mathrm{H}) ;{ }^{13} \mathrm{C}$ NMR $\left(100 \mathrm{MHz},\left(\mathrm{CD}_{3}\right)_{2} \mathrm{CO}\right): \delta=167.0,155.8,143.9$, 141.7, 136.3, $132.8 \quad\left({ }^{2} J_{\mathrm{C}-\mathrm{F}}=31.3 \mathrm{~Hz}\right), 130.4,126.3,122.7 \quad\left({ }^{1} J_{\mathrm{C}-\mathrm{F}}=\right.$ $273.9 \mathrm{~Hz}), 121.9,121.6,116.7\left({ }^{3} J_{\mathrm{C}-\mathrm{F}}=4.8 \mathrm{~Hz}\right), 115.5,109.6,102.9$, $63.9,61.3,32.6,32.5,27.6,14.1 \mathrm{ppm}$; IR (NaCl): $\tilde{v}=3500-3000(\mathrm{br}$, $\mathrm{N}-\mathrm{H}$ and $\mathrm{O}-\mathrm{H}), 2933(\mathrm{~m}, \mathrm{C}-\mathrm{H}), 1678(\mathrm{~m}, \mathrm{C}=\mathrm{O}), 1588(\mathrm{~s}, \mathrm{C}=\mathrm{C}), 1529$ $(\mathrm{s}, \mathrm{C}=\mathrm{C}), 1327 \mathrm{~cm}^{-1}(\mathrm{~s}) ; \mathrm{MS}(\mathrm{ESI}+): 429[\mathrm{M}+\mathrm{Na}]^{+}(23), 407[\mathrm{M}+\mathrm{H}]^{+}$ (100); HRMS $(E S I+): m / z[M+H]^{+}$calcd for $\mathrm{C}_{21} \mathrm{H}_{22} \mathrm{~F}_{3} \mathrm{~N}_{2} \mathrm{O}_{3}: 407.1577$, found: 407.1585

\section{2,2-Dimethyl-5-(3-tert-butyldimethylsilyloxyprop-1-yl)-4H-1,3-} benzodioxin-4-one $(\mathbf{1 1} \mathrm{g})$ : Following the general procedure described for the Suzuki cross coupling (Method A), $9(0.25 \mathrm{~g}$ $0.07 \mathrm{mmol}), 10 \mathrm{~g}(0.11 \mathrm{~g}, 0.65 \mathrm{mmol}), 9-B B N(1.3 \mathrm{~mL}, 0.5 \mathrm{M}$ in THF, $0.65 \mathrm{mmol}), \quad \mathrm{MeONa}(0.04 \mathrm{~g}, 0.65 \mathrm{mmol}), \mathrm{PdCl}_{2}(\mathrm{dppf}) \quad(6 \mathrm{mg}$, $0.02 \mathrm{mmol})$ and $\mathrm{KBr}(0.09 \mathrm{~g}, 0.73 \mathrm{mmol})$ in THF $(5.4 \mathrm{~mL})$ afforded, after purification by column chromatography $(90: 10$, hexane/ EtOAc), $11 \mathrm{~g}$ as a colourless oil $(74 \mathrm{mg}, 32 \%) ;{ }^{1} \mathrm{H} \mathrm{NMR}(400 \mathrm{MHz}$, $\left.\mathrm{CDCl}_{3}\right): \delta=7.41(\mathrm{t}, J=7.9 \mathrm{~Hz}, 1 \mathrm{H}), 6.96(\mathrm{~d}, J=7.6 \mathrm{~Hz}, 1 \mathrm{H}), 6.81(\mathrm{~d}$, $J=8.2 \mathrm{~Hz}, 1 \mathrm{H}), 3.69(\mathrm{t}, J=6.4 \mathrm{~Hz}, 2 \mathrm{H}), 3.14(\mathrm{t}, J=7.7 \mathrm{~Hz}, 2 \mathrm{H}), 1.84$ $(\mathrm{t}, J=6.6 \mathrm{~Hz}, 2 \mathrm{H}), 1.70\left(\mathrm{~s}, 6 \mathrm{H}, 2 \mathrm{CH}_{3}\right), 0.91\left(\mathrm{~s}, 9 \mathrm{H}, \mathrm{SiC}\left(\mathrm{CH}_{3}\right)_{3}\right)$, $0.07 \mathrm{ppm}\left(\mathrm{s}, 6 \mathrm{H}, 2 \mathrm{SiCH}_{3}\right) ;{ }^{13} \mathrm{C} \mathrm{NMR}\left(100 \mathrm{MHz}, \mathrm{CDCl}_{3}\right): \delta=160.2$, $157.1,147.8,135.1,125.2,115.2,112.1,105.0,62.8,34.0,30.7,26.0$ (3C), $25.6(2 \mathrm{C}), 18.3,-5.3 \mathrm{ppm}(2 \mathrm{C})$; IR $(\mathrm{NaCl}): \tilde{v}=2952(\mathrm{~m}, \mathrm{C}-\mathrm{H})$, $2928(\mathrm{~m}, \mathrm{C}-\mathrm{H}), 2887(\mathrm{w}, \mathrm{C}-\mathrm{H}), 2857(\mathrm{~m}, \mathrm{C}-\mathrm{H}), 1739(\mathrm{~s}, \mathrm{C}=\mathrm{O}), 1606$ $(\mathrm{m}, \mathrm{C}=\mathrm{C}), 1582(\mathrm{~m}, \mathrm{C}=\mathrm{C}), 1476(\mathrm{~s}), 1313(\mathrm{~s}), 1271 \mathrm{~cm}^{-1}(\mathrm{~s}) ; \mathrm{MS}$
$(\mathrm{ESI}+): 373[\mathrm{M}+\mathrm{Na}]^{+}(71), 351[\mathrm{M}+\mathrm{H}]^{+}(100) ; \mathrm{HRMS}(\mathrm{ESI}+): \mathrm{m} / \mathrm{z}$ $[M+\mathrm{H}]^{+}$calcd for $\mathrm{C}_{19} \mathrm{H}_{31} \mathrm{O}_{4} \mathrm{Si}: 351.1986$, found: 351.1989 .

$\mathrm{N}$-(4-Cyano-3-(trifluoromethyl)phenyl)-6-(3-tert-butyldimethylsilyloxyprop-1-yl)-2-hydroxybenzamide $(\mathbf{1 3} \mathrm{g})$ : Following the general procedure described for amide formation, the reaction of $11 \mathrm{~g}$ $(0.11 \mathrm{~g}, 0.17 \mathrm{mmol}), 12(0.16 \mathrm{~g}, 0.85 \mathrm{mmol}), n B u L i(0.57 \mathrm{~mL}, 1.50 \mathrm{M}$ in hexane, $0.85 \mathrm{mmol})$ and DMPU $(0.15 \mathrm{~mL}, 1.24 \mathrm{mmol})$ in THF $(6.5 \mathrm{~mL})$ afforded, after purification by column chromatography (80:20, hexane/EtOAc), $\mathbf{1 3} \mathbf{g}$ as a colourless oil (30 mg, 37\%); 'H NMR $\left(400 \mathrm{MHz},\left(\mathrm{CD}_{3}\right)_{2} \mathrm{CO}\right): \delta=10.07(\mathrm{br}, 1 \mathrm{H}), 8.57(\mathrm{~s}, 1 \mathrm{H}), 8.27$ $(\mathrm{d}, J=8.5 \mathrm{~Hz}, 1 \mathrm{H}), 8.06(\mathrm{~d}, J=8.5 \mathrm{~Hz}, 1 \mathrm{H}), 7.22(\mathrm{t}, J=7.9 \mathrm{~Hz}, 1 \mathrm{H})$, 6.9-6.8 (m, 2H), $3.65(\mathrm{t}, J=6.1 \mathrm{~Hz}, 2 \mathrm{H}), 2.75(\mathrm{t}, J=7.8 \mathrm{~Hz}, 2 \mathrm{H}), 1.9-$ $1.8(\mathrm{~m}, 2 \mathrm{H}), 0.83\left(\mathrm{~s}, 9 \mathrm{H}, \mathrm{SiC}\left(\mathrm{CH}_{3}\right)_{3}\right), 0.00 \mathrm{ppm}\left(\mathrm{s}, 6 \mathrm{H}, 2 \mathrm{SiCH}_{3}\right)$; ${ }^{13} \mathrm{C}$ NMR $\left(100 \mathrm{MHz},\left(\mathrm{CD}_{3}\right)_{2} \mathrm{CO}\right): \delta=167.2,154.1,144.0,141.5,136.2$, $132.7\left({ }^{2} J_{\mathrm{C}-\mathrm{F}}=34.5 \mathrm{~Hz}\right), 130.4,124.7,122.7\left({ }^{1} J_{\mathrm{C}-\mathrm{F}}=272.5 \mathrm{~Hz}\right), 121.9$, $120.7,116.7\left({ }^{3} J_{C-F}=5.6 \mathrm{~Hz}\right), 115.6,113.3,102.8,62.3,34.5,29.5,25.3$ (3C), 17.8, -6.1 ppm (2C); IR (NaCl): $\tilde{v}=3500-3000(\mathrm{br}, \mathrm{N}-\mathrm{H}$ and $\mathrm{O}-\mathrm{H}), 2928(\mathrm{~m}, \mathrm{C}-\mathrm{H}), 2858(\mathrm{~m}, \mathrm{C}-\mathrm{H}), 1652(\mathrm{~m}, \mathrm{C}=\mathrm{O}), 1588(\mathrm{~s}, \mathrm{C}=\mathrm{C})$, $1534(\mathrm{~s}, \mathrm{C}=\mathrm{C}), 1427(\mathrm{~s}), 1330 \mathrm{~cm}^{-1}(\mathrm{~s}) ; \mathrm{MS}(\mathrm{ESI}+): 501[\mathrm{M}+\mathrm{Na}]^{+}$ (100), $479[M+\mathrm{H}]^{+}(14)$; HRMS (ESI+): $\mathrm{m} / \mathrm{z}[\mathrm{M}+\mathrm{H}]^{+}$calcd for $\mathrm{C}_{24} \mathrm{H}_{30} \mathrm{~F}_{3} \mathrm{~N}_{2} \mathrm{O}_{3} \mathrm{Si}$ : 479.1972, found: 479.1984.

$\mathrm{N}$-(4-Cyano-3-trifluoromethylphenyl)-2-ethoxy-6-(3-hydroxyprop1-yl)benzamide $(\mathbf{7 g})$ : Following the general procedure described for the alkylation of phenols, the reaction of $13 \mathrm{~g}(0.03 \mathrm{~g}$, $0.07 \mathrm{mmol}), \mathrm{Et}_{2} \mathrm{SO}_{4}(0.02 \mathrm{~mL}, 0.16 \mathrm{mmol})$ and $\mathrm{K}_{2} \mathrm{CO}_{3} \quad(0.03 \mathrm{~g}$, $0.18 \mathrm{mmol})$ in acetone $(2.8 \mathrm{~mL})$ afforded, after purification by column chromatography (80:20, hexane/EtOAc), a colourless oil $(25 \mathrm{mg})$ that was used in the next step without further purification. Following the general procedure described for the deprotection of silyl ethers, the reaction of the residue obtained above $(24 \mathrm{mg}$, $0.047 \mathrm{mmol})$ and TBAF $(0.071 \mathrm{~mL}, 1 \mathrm{M}$ in THF, $0.071 \mathrm{mmol})$ in THF $(0.8 \mathrm{~mL})$ afforded, after purification by column chromatography (60:40, hexane/EtOAc), $\mathbf{7 g}$ as a colourless oil (18 mg, 97\%); ${ }^{1} \mathrm{H}$ NMR $\left(400 \mathrm{MHz},\left(\mathrm{CD}_{3}\right)_{2} \mathrm{CO}\right): \delta=10.08(\mathrm{~s}, 1 \mathrm{H}), 8.49(\mathrm{~s}, 1 \mathrm{H}), 8.25(\mathrm{~d}$, $J=8.4 \mathrm{~Hz}, 1 \mathrm{H}), 8.05(\mathrm{~d}, J=8.5 \mathrm{~Hz}, 1 \mathrm{H}), 7.33(\mathrm{t}, J=8.0 \mathrm{~Hz}, 1 \mathrm{H}), 6.9-$ $6.8(\mathrm{~m}, 2 \mathrm{H}), 4.07(\mathrm{q}, J=7.0 \mathrm{~Hz}, 2 \mathrm{H}), 3.6-3.5(\mathrm{~m}, 2 \mathrm{H}), 2.74(\mathrm{t}, J=$ $8.5 \mathrm{~Hz}, 2 \mathrm{H}), 1.9-1.8(\mathrm{~m}, 2 \mathrm{H}), 1.29 \mathrm{ppm}(\mathrm{t}, J=6.9 \mathrm{~Hz}, 3 \mathrm{H}) ;{ }^{13} \mathrm{C}$ NMR $\left(100 \mathrm{MHz},\left(\mathrm{CD}_{3}\right)_{2} \mathrm{CO}\right): \delta=169.0,157.7,145.8,143.3,138.2,134.7$ $\left({ }^{2} J_{\mathrm{C}-\mathrm{F}}=31.0 \mathrm{~Hz}\right), 132.4,128.4,125.1\left({ }^{1} J_{\mathrm{C}-\mathrm{F}}=270.6 \mathrm{~Hz}\right), 123.9,123.5$, $118.7\left({ }^{3} J_{C-F}=4.9 \mathrm{~Hz}\right), 117.4,111.6,104.8,65.9,62.7,36.2,31.1$, $16.0 \mathrm{ppm}$; IR (NaCl): $\tilde{v}=3500-3200(\mathrm{br}, \mathrm{N}-\mathrm{H}$ and $\mathrm{O}-\mathrm{H}), 2928(\mathrm{~m}$, $\mathrm{C}-\mathrm{H}), 1671(\mathrm{~m}, \mathrm{C}=\mathrm{O}), 1589(\mathrm{~s}, \mathrm{C}=\mathrm{C}), 1526(\mathrm{~s}, \mathrm{C}=\mathrm{C}), 1327(\mathrm{~s})$, $1220 \mathrm{~cm}^{-1}(\mathrm{~s}) ; \mathrm{MS}(\mathrm{ESI}+)$ : $415[\mathrm{M}+\mathrm{Na}]^{+}(100), 393[\mathrm{M}+\mathrm{H}]^{+}(65)$; HRMS $(\mathrm{ESI}+): \mathrm{m} / \mathrm{z}[\mathrm{M}+\mathrm{H}]^{+}$calcd for $\mathrm{C}_{20} \mathrm{H}_{20} \mathrm{~F}_{3} \mathrm{~N}_{2} \mathrm{O}_{3}: 393.1421$, found: 393.1419.

5-Ethoxy-2,2-dimethyl-4H-1,3-benzodioxin-4-one (16): Following the general procedure described for the alkylation of phenols, the reaction of $15(0.10 \mathrm{~g}, 0.51 \mathrm{mmol}), \mathrm{K}_{2} \mathrm{CO}_{3}(0.18 \mathrm{~g}, 1.28 \mathrm{mmol})$ and ethyl iodide $(0.09 \mathrm{~mL}, 1.13 \mathrm{mmol})$ in acetone $(16 \mathrm{~mL})$, afforded, after purification by column chromatography $(90: 10$, hexane/ EtOAc), 16 as a white solid $(0.106 \mathrm{~g}, 91 \%) ; \mathrm{mp}: 101^{\circ} \mathrm{C}$ (hexane/acetone); ${ }^{1} \mathrm{H}$ NMR $\left(400 \mathrm{MHz}, \mathrm{CDCl}_{3}\right): \delta=7.42(\mathrm{t}, J=8.4 \mathrm{~Hz}, 1 \mathrm{H}), 6.62(\mathrm{~d}$ $J=8.4 \mathrm{~Hz}, 1 \mathrm{H}), 6.55(\mathrm{~d}, J=8.4 \mathrm{~Hz}, 1 \mathrm{H}), 4.19(\mathrm{q}, J=6.8 \mathrm{~Hz}, 2 \mathrm{H}), 1.72$ $\left(\mathrm{s}, 6 \mathrm{H}, 2 \mathrm{CH}_{3}\right), 1.53 \mathrm{ppm}(\mathrm{t}, J=6.8 \mathrm{~Hz}, 3 \mathrm{H}) ;{ }^{13} \mathrm{C} \mathrm{NMR}(100 \mathrm{MHz}$, $\left.\mathrm{CDCl}_{3}\right): \delta=160.7,158.0,157.6,136.2,108.8,106.3,105.0,103.3$, 64.8, $25.5(2 \mathrm{C}), 14.4 \mathrm{ppm}$; IR (NaCl): $\tilde{v}=2988(\mathrm{w}, \mathrm{C}-\mathrm{H}), 2938(\mathrm{w}, \mathrm{C}-$ H), $2888(w, C-H), 1736(s, C=0), 1582(m, C=C), 1461(s), 1254(s)$, $1081 \mathrm{~cm}^{-1}$ (s); MS (ESI+): $245[M+N a]^{+}(100), 223[M+\mathrm{H}]^{+}(46)$; HRMS (ESI +): $\mathrm{m} / z[\mathrm{M}+\mathrm{Na}]^{+}$calcd for $\mathrm{C}_{12} \mathrm{H}_{14} \mathrm{NaO}_{4}: 245.0784$; found 245.0779; Anal. calcd for $\mathrm{C}_{12} \mathrm{H}_{14} \mathrm{O}_{4}$ : $\mathrm{C}, 64.85 ; \mathrm{H}, 6.35$; found: $\mathrm{C}$, 64.76; H, 6.38 . 
$\mathrm{N}$-(4-Cyano-3-trifluoromethylphenyl)-6-ethoxy-2-hydroxybenz-

amide (17): Following the general procedure described for amide formation, the reaction of $16(0.34 \mathrm{~g}, 1.51 \mathrm{mmol}), 12(0.703 \mathrm{~g}$, $3.78 \mathrm{mmol}), n$ BuLi $(3.10 \mathrm{~mL}, 1.22 \mathrm{M}$ in hexane, $3.78 \mathrm{mmol})$ and DMPU $(4.15 \mathrm{~mL}, 34.50 \mathrm{mmol})$ in THF $(56 \mathrm{~mL})$ afforded, after purification by column chromatography $(60: 10: 30$, hexane/EtOAc/ $\left.\mathrm{CH}_{2} \mathrm{Cl}_{2}\right), 17$ as a white solid $(0.47 \mathrm{~g}, 88 \%) ; \mathrm{mp}: 167^{\circ} \mathrm{C}$ (hexane/acetone); ${ }^{1} \mathrm{H}$ NMR $\left(400 \mathrm{MHz},\left(\mathrm{CD}_{3}\right)_{2} \mathrm{CO}\right): \delta=11.06(\mathrm{~s}, 1 \mathrm{H}), 8.40(\mathrm{~s}, 1 \mathrm{H})$, 8.1-8.0 (m, 2H), $7.43(\mathrm{t}, J=8.4 \mathrm{~Hz}, 1 \mathrm{H}), 6.67(\mathrm{~d}, J=8.4 \mathrm{~Hz}, 1 \mathrm{H}), 6.61$ $(\mathrm{dd}, J=8.4,0.9 \mathrm{~Hz}, 1 \mathrm{H}), 4.38(\mathrm{q}, J=7.0 \mathrm{~Hz}, 2 \mathrm{H}), 1.66 \mathrm{ppm}(\mathrm{t}, J=$ $7.0 \mathrm{~Hz}, 3 \mathrm{H}) ;{ }^{13} \mathrm{C}$ NMR $\left(100 \mathrm{MHz},\left(\mathrm{CD}_{3}\right)_{2} \mathrm{CO}\right): \delta=171.3,166.4,160.0$, $144.1,138.1,137.0,134.7 \quad\left({ }^{2} J_{C-F}=32.5 \mathrm{~Hz}\right), 125.6,124.5 \quad\left({ }^{1} J_{C-F}=\right.$ $273.4 \mathrm{~Hz}), 120.2\left({ }^{3} J_{\mathrm{C}-\mathrm{F}}=5.6 \mathrm{~Hz}\right), 117.2,113.2,106.0\left({ }^{4} J_{\mathrm{C}-\mathrm{F}}=2.6 \mathrm{~Hz}\right)$, 105.7, 104.6, 67.8, $15.8 \mathrm{ppm}$; IR (NaCl): $\tilde{v}=3600-3000(\mathrm{br}, \mathrm{N}-\mathrm{H}$ and O-H), $1648(\mathrm{~m}, \mathrm{C}=\mathrm{O}), 1585(\mathrm{~s}, \mathrm{C}=\mathrm{C}), 1544(\mathrm{~s}, \mathrm{C}=\mathrm{C}), 1451(\mathrm{~m}), 1430$ $(\mathrm{m}), 1326(\mathrm{~s}), 1234(\mathrm{~s}), 1136 \mathrm{~cm}^{-1}(\mathrm{~s}) ; \mathrm{MS}(\mathrm{ESI}+): 373[\mathrm{M}+\mathrm{Na}]^{+}(20)$, $351[\mathrm{M+H}]^{+}$(92), 209 (100); HRMS (ESI+): $\mathrm{m} / \mathrm{z}[\mathrm{M+H}]^{+}$calcd for $\mathrm{C}_{17} \mathrm{H}_{14} \mathrm{~F}_{3} \mathrm{~N}_{2} \mathrm{O}_{3}$ : 351.0951; found 351.0965; Anal. calcd for $\mathrm{C}_{17} \mathrm{H}_{13} \mathrm{~F}_{3} \mathrm{~N}_{2} \mathrm{O}_{3}$ : C, 58.29; $\mathrm{H}, 3.74$; found: $\mathrm{C}, 58.25 ; \mathrm{H}, 3.76$.

2-(4-Cyano-3-trifluoromethylphenylcarbamoyl)-3-ethoxyphenyl trifluoromethanesulfonate (18): Following the general procedure described for the synthesis of triflates, the reaction of $17(0.15 \mathrm{~g}$, $0.43 \mathrm{mmol})$ and trifluoromethanesulfonic anhydride $(0.07 \mathrm{~mL}$, $0.43 \mathrm{mmol})$ in pyridine $(0.75 \mathrm{~mL})$ afforded, after purification by column chromatography (70:30, hexane/EtOAc), 18 as a white solid $(0.18 \mathrm{~g}, 87 \%)$; mp: $148{ }^{\circ} \mathrm{C}$ (hexane/EtOAc); ${ }^{1} \mathrm{H}$ NMR $(400 \mathrm{MHz}$, $\left.\mathrm{CDCl}_{3}\right): \delta=8.52(\mathrm{~s}, 1 \mathrm{H}), 8.02(\mathrm{~d}, J=9.2 \mathrm{~Hz}, 1 \mathrm{H}), 7.96(\mathrm{~s}, 1 \mathrm{H}), 7.79(\mathrm{~d}$, $J=8.4 \mathrm{~Hz}, 1 \mathrm{H}), 7.49(\mathrm{t}, J=8.4 \mathrm{~Hz}, 1 \mathrm{H}), 7.03(\mathrm{~d}, J=8.8 \mathrm{~Hz}, 1 \mathrm{H}), 6.98$ $(\mathrm{d}, J=8.4 \mathrm{~Hz}, 1 \mathrm{H}), 4.19(\mathrm{q}, J=7.2 \mathrm{~Hz}, 2 \mathrm{H}), 1.46 \mathrm{ppm}(\mathrm{t}, J=7.2 \mathrm{~Hz}$, $3 \mathrm{H}) ;{ }^{13} \mathrm{C}$ NMR $\left(100 \mathrm{MHz}, \mathrm{CDCl}_{3}\right): \delta=161.0,157.0,147.6,141.7$, 136.0, $134.1\left({ }^{2} J_{\mathrm{C}-\mathrm{F}}=33.2 \mathrm{~Hz}\right), 132.8,122.2,122.1\left({ }^{1} J_{\mathrm{C}-\mathrm{F}}=274.0 \mathrm{~Hz}\right)$, 118.6, $118.5\left({ }^{1} J_{\mathrm{C}-\mathrm{F}}=320.6 \mathrm{~Hz}\right), 117.3\left({ }^{3} J_{\mathrm{C}-\mathrm{F}}=4.9 \mathrm{~Hz}\right), 115.5,114.9$, 112.5, 104.8, 65.7, 14.6 ppm; IR (NaCl): $\tilde{v}=3286(\mathrm{~m}, \mathrm{~N}-\mathrm{H}), 2979(\mathrm{w}$ $\mathrm{C}-\mathrm{H}), 1650(\mathrm{~m}, \mathrm{C}=\mathrm{O}), 1582(\mathrm{~s}, \mathrm{C}=\mathrm{C}), 1545(\mathrm{~s}, \mathrm{C}=\mathrm{C}), 1431(\mathrm{~s}, \mathrm{C}=\mathrm{C})$, $1322 \mathrm{~cm}^{-1}(\mathrm{~s}) ; \mathrm{MS}(\mathrm{ESI}+): 505[\mathrm{M}+\mathrm{Na}]^{+}(91), 483[\mathrm{M+H}]^{+}(100)$; HRMS $(\mathrm{ESI}+): \mathrm{m} / \mathrm{z}[\mathrm{M}+\mathrm{H}]^{+}$calcd for $\mathrm{C}_{18} \mathrm{H}_{13} \mathrm{~F}_{6} \mathrm{~N}_{2} \mathrm{O}_{5} \mathrm{~S}: 483.0444$, found: 483.0446; Anal. calcd for $\mathrm{C}_{18} \mathrm{H}_{12} \mathrm{~F}_{6} \mathrm{~N}_{2} \mathrm{O}_{5} \mathrm{~S}$ : C, 44.82; $\mathrm{H}, 2.51$; found: $\mathrm{C} ; 44.63 ; \mathrm{H}, 1.98$.

(E)-4,4,5,5-Tetramethyl-2-(4-trifluoromethylphenyl-vin-1-yl)-1,3,2dioxaborolane (20 a): General procedure for the Takai-Utimoto reaction. A suspension of $\mathrm{CrCl}_{3}(2.76 \mathrm{~g}, 22.43 \mathrm{mmol})$ in THF $(30 \mathrm{~mL})$ was treated with $19 \mathrm{a}(0.38 \mathrm{~mL}, 2.80 \mathrm{mmol})$ and 3 -(dichloromethyl)4,4,5,5-tetramethyl-1,3,2-dioxaborolane $(1.18 \mathrm{~g}, 5.60 \mathrm{mmol})$ in THF $(6 \mathrm{~mL})$. Then Lil $(1.50 \mathrm{~g}, 11.20 \mathrm{mmol})$ in THF $(6 \mathrm{~mL})$ was added and the suspension was stirred for $16 \mathrm{~h}$ at RT. The mixture was poured into water, extracted with EtOAc $(\times 3)$, and the solvent was evaporated. The residue was purified by column chromatography $(95: 5$, hexane/EtOAc) to afford $20 \mathrm{a}$ as a white solid $(0.68 \mathrm{~g}, 81 \%)$; $\mathrm{mp}$ : $60^{\circ} \mathrm{C}$ (hexane/EtOAc); ${ }^{1} \mathrm{H}$ NMR $\left(400 \mathrm{MHz}, \mathrm{CDCl}_{3}\right): \delta=7.6-7.5(\mathrm{~m}$, $4 \mathrm{H}), 7.39(\mathrm{~d}, J=18.4 \mathrm{~Hz}, 1 \mathrm{H}), 6.25(\mathrm{~d}, J=18.4 \mathrm{~Hz}, 1 \mathrm{H}), 1.28 \mathrm{ppm}(\mathrm{s}$, $\left.12 \mathrm{H}, 4 \mathrm{CH}_{3}\right) ;{ }^{13} \mathrm{C} \mathrm{NMR}\left(100 \mathrm{MHz}, \mathrm{CDCl}_{3}\right): \delta=147.6,140.8,130.4$ $\left({ }^{2} J_{\mathrm{C}-\mathrm{F}}=32.5 \mathrm{~Hz}\right), 127.1(2 \mathrm{C}), 125.5\left({ }^{3} J_{\mathrm{C}-\mathrm{F}}=4.2 \mathrm{~Hz}, 2 \mathrm{C}\right), 124.1\left({ }^{1} \mathrm{~J}_{\mathrm{C}-\mathrm{F}}=\right.$ $274.7 \mathrm{~Hz}), 119.5,83.5(2 \mathrm{C}), 24.7 \mathrm{ppm}(4 \mathrm{C})$; IR ( $\mathrm{NaCl}): \tilde{v}=2923(\mathrm{~s}, \mathrm{C}-$ H), $2853(\mathrm{~m}, \mathrm{C}-\mathrm{H}), 1623 \mathrm{~cm}^{-1}(\mathrm{w}, \mathrm{C}=\mathrm{C})$; MS $(\mathrm{ESI}+): 321[\mathrm{M}+\mathrm{Na}]^{+}$ (72), $299[\mathrm{M}+\mathrm{H}]^{+}(100), 279(20) ; \mathrm{HRMS}(\mathrm{ESI}+): \mathrm{m} / \mathrm{z}[\mathrm{M}+\mathrm{H}]^{+}$calcd for $\mathrm{C}_{15} \mathrm{H}_{19} \mathrm{BF}_{3} \mathrm{O}_{2}$ : 299.1427, found: 299.1438; Anal. calcd for $\mathrm{C}_{15} \mathrm{H}_{18} \mathrm{BF}_{3} \mathrm{O}_{2}$ : C, 60.43; $\mathrm{H}, 6.09$; found: $\mathrm{C}, 60.49 ; \mathrm{H}, 6.09$.

(E)-4,4,5,5-Tetramethyl-2-(3-bromophenyl)ethen-1-yl-1,3,2-dioxaborolane (20 b): Following the general procedure described for the Takai-Utimoto reaction, $19 \mathrm{~b}(0.33 \mathrm{~mL}, 2.80 \mathrm{mmol})$, 3-(dichloromethyl)-4,4,5,5-tetramethyl-1,3,2-dioxaborolane $(1.18 \mathrm{~g}, 5.60 \mathrm{mmol})$, $\mathrm{CrCl}_{3}(2.76 \mathrm{~g}, 22.43 \mathrm{mmol})$ and Lil $(1.50 \mathrm{~g}, 11.20 \mathrm{mmol})$ in THF
$(42 \mathrm{~mL})$ afforded, after purification by column chromatography (95:5, hexane/EtOAc), $20 \mathrm{~b}$ as a yellow oil $(0.78 \mathrm{~g}, 91 \%) ;{ }^{1} \mathrm{H}$ NMR $\left(400 \mathrm{MHz}, \mathrm{CDCl}_{3}\right): \delta=7.63(\mathrm{t}, J=1.7 \mathrm{~Hz}, 1 \mathrm{H}), 7.42(\mathrm{td}, J=8.0,1.6 \mathrm{~Hz}$, $2 \mathrm{H}), 7.32(\mathrm{~d}, J=18.4 \mathrm{~Hz}, 1 \mathrm{H}), 7.23(\mathrm{t}, J=7.6 \mathrm{~Hz}, 1 \mathrm{H}), 6.18(\mathrm{~d}, J=$ $18.4 \mathrm{~Hz}, 1 \mathrm{H}), 1.33 \mathrm{ppm}(\mathrm{s}, 12 \mathrm{H}) ;{ }^{13} \mathrm{C}$ NMR $\left(100 \mathrm{MHz}, \mathrm{CDCl}_{3}\right): \delta=$ $147.5,139.5,131.5,129.9$ (2C), 129.7, 125.4, 122.6, 83.3 (2C), $24.7 \mathrm{ppm}(4 \mathrm{C})$; $\mathrm{MS}(\mathrm{ESI}+): 429[\mathrm{M}+\mathrm{Na}]^{+}(23), 407[\mathrm{M}+\mathrm{H}]^{+}(100)$; IR (NaCl): $\tilde{v}=2979(\mathrm{~m}, \mathrm{C}-\mathrm{H}), 1626(\mathrm{~m}, \mathrm{C}=\mathrm{O}), 1563(\mathrm{w}, \mathrm{C}=\mathrm{C}), 1471$ (w), $1345(\mathrm{~s}), 1210(\mathrm{~m}), 1145 \mathrm{~cm}^{-1}(\mathrm{~s}) ; \mathrm{MS}(\mathrm{ESI}+): 333[\mathrm{M}+\mathrm{Na}]^{+}$ (51), $331[\mathrm{M}+\mathrm{Na}]^{+}(62), 311[\mathrm{M}+\mathrm{H}]^{+}(100), 309[\mathrm{M}+\mathrm{H}]^{+}(100)$; HRMS $(\mathrm{ESI}+): \mathrm{m} / \mathrm{z}[\mathrm{M}+\mathrm{H}]^{+}$calcd for $\mathrm{C}_{14} \mathrm{H}_{19} \mathrm{~B}^{79} \mathrm{BrO}_{2}: 309.0659$, found: 309.0667 .

\section{(E)-N-(4-Cyano-3-trifluoromethylphenyl)-2-ethoxy-6-phenyl-}

ethen-1-yl Benzamide (7j): General procedure for the Suzuki cross coupling (Method B). $21 \quad(41.9 \mathrm{mg}, 0.19 \mathrm{mmol}), 18$ (0.05 g, $0.11 \mathrm{mmol}), \quad \mathrm{Pd}\left(\mathrm{PPh}_{3}\right)_{4} \quad(6 \mathrm{mg}, 5.2 \mu \mathrm{mol})$ and $\mathrm{K}_{3} \mathrm{PO}_{4} \quad(0.04 \mathrm{~g}$, $0.19 \mathrm{mmol})$ were suspended in dioxane $(0.55 \mathrm{~mL})$. The suspension was irradiated in a microwave reactor for $15 \mathrm{~min}$ at $100^{\circ} \mathrm{C}(90 \mathrm{~W})$. Benzene $(1 \mathrm{~mL})$, aq $\mathrm{NaOH}(100 \mu \mathrm{L}, 3 \mathrm{M})$ and $\mathrm{H}_{2} \mathrm{O}_{2}(30 \%, 100 \mu \mathrm{L})$ were added and the mixture was stirred at RT for $1 \mathrm{~h}$. Water was added and the aqueous layer was extracted with EtOAc $(\times 3)$. The combined organic layers were dried $\left(\mathrm{Na}_{2} \mathrm{SO}_{4}\right)$ and the solvent was evaporated. The residue was purified by column chromatography (-NH $\mathrm{N}_{2}$ silica gel; 90:10, hexane/EtOAc) to afford $7 \mathbf{j}$ as a white solid (36.8 mg, 80\%); mp: $182^{\circ} \mathrm{C}$ (hexane/acetone); ${ }^{1} \mathrm{H}$ NMR $(400 \mathrm{MHz}$, $\left.\left(\mathrm{CD}_{3}\right)_{2} \mathrm{CO}\right): \delta=10.16(\mathrm{~s}, 1 \mathrm{H}), 8.50(\mathrm{~s}, 1 \mathrm{H}), 8.29(\mathrm{dd}, J=8.5,1.4 \mathrm{~Hz}$, $1 \mathrm{H}), 8.07(\mathrm{~d}, J=8.5 \mathrm{~Hz}, 1 \mathrm{H}), 7.6-7.4(\mathrm{~m}, 4 \mathrm{H}), 7.4-7.2(\mathrm{~m}, 5 \mathrm{H}), 7.03$ $(\mathrm{dd}, J=7.7,1.3 \mathrm{~Hz}, 1 \mathrm{H}), 4.12(\mathrm{q}, J=7.0 \mathrm{~Hz}, 2 \mathrm{H}), 1.31 \mathrm{ppm}(\mathrm{t}, J=$ $7.0 \mathrm{~Hz}, 3 \mathrm{H}) ;{ }^{13} \mathrm{C}$ NMR $\left(100 \mathrm{MHz},\left(\mathrm{CD}_{3}\right)_{2} \mathrm{CO}\right): \delta=168.4,158.0,145.8$, 139.0, 138.3, 138.2, $134.7\left({ }^{2} J_{\mathrm{C}-\mathrm{F}}=34.6 \mathrm{~Hz}\right), 133.5,132.6,130.6(2 \mathrm{C})$, $129.9,128.6(2 \mathrm{C}), 127.7,126.7,124.6\left({ }^{1} J_{\mathrm{C}-\mathrm{F}}=272.0 \mathrm{~Hz}\right), 123.9,119.3$, $118.7\left({ }^{3} J_{\mathrm{C}-\mathrm{F}}=5.6 \mathrm{~Hz}\right), 117.4,113.1,105.0,66.1,16.0 \mathrm{ppm}$; IR $(\mathrm{NaCl})$ : $\tilde{v}=3292(\mathrm{br}, \mathrm{N}-\mathrm{H}), 2964(\mathrm{~s}, \mathrm{C}-\mathrm{H}), 1668(\mathrm{~s}, \mathrm{C}=\mathrm{O}), 1587(\mathrm{~s}, \mathrm{C}=\mathrm{C})$, $1530(\mathrm{~s}, \mathrm{C}=\mathrm{C}), 1426(\mathrm{~m}), 1260(\mathrm{~s}), 1137 \mathrm{~cm}^{-1}(\mathrm{~s}) ; \mathrm{MS}(\mathrm{ESI}+): 459$ $[M+N a]^{+}(38), 437[M+H]^{+}(100), 391$ (38); HRMS (ESI+): $\mathrm{m} / \mathrm{z}$ $[M+\mathrm{H}]^{+}$calcd for $\mathrm{C}_{25} \mathrm{H}_{20} \mathrm{~F}_{3} \mathrm{~N}_{2} \mathrm{O}_{2}: 437.1471$, found: 437.1468 .

(E)-N-(4-Cyano-3-trifluoromethylphenyl)-2-ethoxy-6-(4-trifluoromethylphenyl-ethen-1-yl benzamide ( $7 \mathrm{~h})$ : Following the general procedure described for the Suzuki cross coupling (Method B), the reaction of $20 \mathrm{a}(0.06 \mathrm{~g}, 0.19 \mathrm{mmol}), 18(0.05 \mathrm{~g}, 0.11 \mathrm{mmol})$, $\mathrm{Pd}\left(\mathrm{PPh}_{3}\right)_{4}(6 \mathrm{mg}, 5.19 \mu \mathrm{mol})$ and $\mathrm{K}_{3} \mathrm{PO}_{4}(0.04 \mathrm{~g}, 0.19 \mathrm{mmol})$ in dioxane $(0.55 \mathrm{~mL})$ afforded, after purification by column chromatography $\left(-\mathrm{NH}_{2}\right.$ silica gel; $90: 10 \rightarrow 85: 15$, hexane/EtOAc), $7 \mathbf{h}$ as a white solid $(22.7 \mathrm{mg}, 43 \%) ; \mathrm{mp}: 180^{\circ} \mathrm{C}$ (hexane/acetone); ${ }^{1} \mathrm{H} N M R$ $\left(400 \mathrm{MHz},\left(\mathrm{CD}_{3}\right)_{2} \mathrm{CO}\right): \delta=10.19(\mathrm{~s}, 1 \mathrm{H}), 8.50(\mathrm{~s}, 1 \mathrm{H}), 8.28(\mathrm{dd}, J=8.5$, $1.0 \mathrm{~Hz}, 1 \mathrm{H}), 8.07(\mathrm{~d}, J=8.5 \mathrm{~Hz}, 1 \mathrm{H}), 7.71(\mathrm{~d}, J=8.4 \mathrm{~Hz}, 2 \mathrm{H}), 7.67(\mathrm{~d}$, $J=8.4 \mathrm{~Hz}, 2 \mathrm{H}), 7.5-7.4(\mathrm{~m}, 3 \mathrm{H}), 7.36(\mathrm{~d}, J=16.3 \mathrm{~Hz}, 1 \mathrm{H}), 7.08(\mathrm{~d}, J=$ $7.9 \mathrm{~Hz}, 1 \mathrm{H}), 4.13(\mathrm{q}, J=7.0 \mathrm{~Hz}, 2 \mathrm{H}), 1.32 \mathrm{ppm}(\mathrm{t}, J=7.0 \mathrm{~Hz}, 3 \mathrm{H})$; ${ }^{13} \mathrm{C}$ NMR $\left(100 \mathrm{MHz},\left(\mathrm{CD}_{3}\right)_{2} \mathrm{CO}\right): \delta=168.2,158.1,145.7,142.9,138.3$, $137.8,134.7 \quad\left({ }^{2} J_{C-F}=32.5 \mathrm{~Hz}\right), 132.8,131.9,130.7 \quad\left({ }^{2} J_{C-F}=32.5 \mathrm{~Hz}\right)$, $129.7,129.1(2 \mathrm{C}), 127.9,127.5\left({ }^{3} J_{\mathrm{C}-\mathrm{F}}=3.9 \mathrm{~Hz}, 2 \mathrm{C}\right), 126.3\left({ }^{1} J_{\mathrm{C}-\mathrm{F}}=\right.$ $271.7 \mathrm{~Hz}), 124.6\left({ }^{1} J_{\mathrm{C}-\mathrm{F}}=273.8 \mathrm{~Hz}\right), 124.0,119.6,118.7\left({ }^{3} J_{\mathrm{C}-\mathrm{F}}=4.9 \mathrm{~Hz}\right)$, $117.4,113.8,105.1,66.2,16.0 \mathrm{ppm}$; IR (NaCl): $\tilde{v}=3500-3200(\mathrm{br}, \mathrm{N}-$ H), $2963(\mathrm{~m}, \mathrm{C}-\mathrm{H}), 2931(\mathrm{~m}, \mathrm{C}-\mathrm{H}), 1666(\mathrm{~m}, \mathrm{C}=\mathrm{O}), 1588(\mathrm{~s}, \mathrm{C}=\mathrm{C})$, $1531(\mathrm{~s}, \mathrm{C}=\mathrm{C}), 1326(\mathrm{~s}), 1121 \mathrm{~cm}^{-1}(\mathrm{~s}) ; \mathrm{MS}(\mathrm{ESI}+)$ : $527[\mathrm{M}+\mathrm{Na}]^{+}$ (48), $505[\mathrm{M+H}]^{+}(71), 391(100)$; HRMS (ESI +): $\mathrm{m} / \mathrm{z}[\mathrm{M}+\mathrm{H}]^{+}$calcd for $\mathrm{C}_{26} \mathrm{H}_{19} \mathrm{~F}_{6} \mathrm{~N}_{2} \mathrm{O}_{2}: 505.1345$, found: 505.1343 .

(E)-N-(4-Cyano-3-trifluoromethylphenyl)-2-ethoxy-6-(3-bromophenyl)ethen-1-yl benzamide (7i): Following the general procedure described for the Suzuki cross coupling (Method B), the reaction of $20 \mathrm{~b}(58.4 \mathrm{mg}, 0.19 \mathrm{mmol}), 18(50 \mathrm{mg}, 0.11 \mathrm{mmol}), \mathrm{Pd}\left(\mathrm{PPh}_{3}\right)_{4}$ $(6 \mathrm{mg}, 5.19 \mu \mathrm{mol})$ and $\mathrm{K}_{3} \mathrm{PO}_{4}(40.1 \mathrm{mg}, 0.19 \mathrm{mmol})$ in dioxane 
$(0.55 \mathrm{~mL})$ afforded, after purification by column chromatography $\left(-\mathrm{NH}_{2}\right.$ silica gel; $90: 10 \rightarrow 85: 15$, hexane/EtOAc), $7 \mathbf{i}$ as a white solid (15 mg, 27\%); mp: $144^{\circ} \mathrm{C}$ (hexane/acetone); ${ }^{1} \mathrm{H} \mathrm{NMR}(400 \mathrm{MHz}$, $\left.\left(\mathrm{CD}_{3}\right)_{2} \mathrm{CO}\right): \delta=10.17(\mathrm{~s}, 1 \mathrm{H}), 8.49(\mathrm{~d}, J=1.6 \mathrm{~Hz}, 1 \mathrm{H}), 8.28(\mathrm{dd}, J=$ $8.4,1.6 \mathrm{~Hz}, 1 \mathrm{H}), 8.07(\mathrm{~d}, J=8.6 \mathrm{~Hz}, 1 \mathrm{H}), 7.68(\mathrm{t}, J=1.7 \mathrm{~Hz}, 1 \mathrm{H}), 7.52$ $(\mathrm{d}, J=7.8 \mathrm{~Hz}, 1 \mathrm{H}), 7.5-7.4(\mathrm{~m}, 3 \mathrm{H}), 7.39(\mathrm{~d}, J=16.3 \mathrm{~Hz}, 1 \mathrm{H}), 7.30(\mathrm{t}$, $J=7.9 \mathrm{~Hz}, 1 \mathrm{H}), 7.25(\mathrm{~d}, J=16.3 \mathrm{~Hz}, 1 \mathrm{H}), 7.06(\mathrm{dd}, J=6.7,2.4 \mathrm{~Hz}$, $1 \mathrm{H}), 4.12(\mathrm{q}, J=7.0 \mathrm{~Hz}, 2 \mathrm{H}), 1.31 \mathrm{ppm}(\mathrm{t}, J=7.0 \mathrm{~Hz}, 3 \mathrm{H}) ;{ }^{13} \mathrm{C} \mathrm{NMR}$ $\left(100 \mathrm{MHz},\left(\mathrm{CD}_{3}\right)_{2} \mathrm{CO}\right): \delta=168.2,158.0,145.7,141.5,138.3,138.0$ $134.6\left({ }^{2} J_{C-F}=31.2 \mathrm{~Hz}\right), 132.7,132.6,132.5,131.9,131.4,128.6,127.8$, $127.3,124.6\left({ }^{1} J_{C-F}=272.7 \mathrm{~Hz}\right), 124.3,124.0,119.6,118.7 \quad\left({ }^{3} J_{C-F}=\right.$ $4.9 \mathrm{~Hz}), 117.4,113.6,105.0,66.1,16.0 \mathrm{ppm}$; IR (NaCl): $\tilde{v}=3500-3200$ (br, N-H), 2980 (w, C-H), 2937 (w, C-H), 2891 (w), 1654 (s, C=O), $1584(\mathrm{~s}, \mathrm{C}=\mathrm{C}), 1510(\mathrm{~s}, \mathrm{C}=\mathrm{C}), 1424(\mathrm{~s}), 1271(\mathrm{~s}), 1178(\mathrm{~s}), 1133 \mathrm{~cm}^{-1}$ (s); MS $(\mathrm{ESI}+): 539[\mathrm{M}+\mathrm{Na}]^{+}(28), 537[\mathrm{M}+\mathrm{Na}]^{+}(28), 515[\mathrm{M}+\mathrm{H}]^{+}$ (31), $515[M+\mathrm{H}]^{+}(31), 38(100) ; \mathrm{HRMS}(\mathrm{ESI}+): \mathrm{m} / \mathrm{z}[\mathrm{M}+\mathrm{H}]^{+}$calcd for $\mathrm{C}_{25} \mathrm{H}_{19} \mathrm{BrF}_{3} \mathrm{~N}_{2} \mathrm{O}_{2}$ : 515.0577, found: 515.0585; Anal. calcd for $\mathrm{C}_{25} \mathrm{H}_{18} \mathrm{BrF}_{3} \mathrm{~N}_{2} \mathrm{O}_{2}: \mathrm{C}, 58.27 ; \mathrm{H}, 3.52$; found: $\mathrm{C}, 58.03 ; \mathrm{H}, 3.62$.

(E)-N-(4-Cyano-3-trifluoromethylphenyl)-2-ethoxy-6-(6-hydroxyhex-1-enyl)benzamide ( $7 \mathrm{k}$ ): Following the general procedure described for the Suzuki cross coupling (Method B), the reaction of $22(27.2 \mathrm{mg}, 0.19 \mathrm{mmol}), 18(50 \mathrm{mg}, 0.11 \mathrm{mmol}), \mathrm{Pd}\left(\mathrm{PPh}_{3}\right)_{4}(6 \mathrm{mg}$, $5.19 \mu \mathrm{mol})$ and $\mathrm{K}_{3} \mathrm{PO}_{4}(40.1 \mathrm{mg}, 0.19 \mathrm{mmol})$ in dioxane $(0.55 \mathrm{~mL})$ af forded, after purification by column chromatography $\left(-\mathrm{NH}_{2}\right.$ silica gel; $90: 10 \rightarrow 55: 45$, hexane/EtOAc), $7 \mathrm{k}$ as a colourless oil $(43.5 \mathrm{mg}$, $92 \%)$; ${ }^{1} \mathrm{H}$ NMR $\left(400 \mathrm{MHz},\left(\mathrm{CD}_{3}\right)_{2} \mathrm{CO}\right): \delta=10.09(\mathrm{~s}, 1 \mathrm{H}), 8.50(\mathrm{~s}, 1 \mathrm{H})$, $8.25(\mathrm{~d}, J=8.5 \mathrm{~Hz}, 1 \mathrm{H}), 8.05(\mathrm{~d}, J=8.5 \mathrm{~Hz}, 1 \mathrm{H}), 7.34(\mathrm{t}, J=8.1 \mathrm{~Hz}$, $1 \mathrm{H}), 7.22(\mathrm{~d}, J=7.9 \mathrm{~Hz}, 1 \mathrm{H}), 6.94(\mathrm{~d}, J=8.2 \mathrm{~Hz}, 1 \mathrm{H}), 6.53(\mathrm{~d}, J=$ $15.7 \mathrm{~Hz}, 1 \mathrm{H}), 6.32(\mathrm{td}, J=15.6,7.0 \mathrm{~Hz}, 1 \mathrm{H}), 4.08(\mathrm{q}, J=6.9 \mathrm{~Hz}, 2 \mathrm{H})$, $3.49(\mathrm{q}, J=5.7 \mathrm{~Hz}, 2 \mathrm{H}), 3.4-3.3(\mathrm{~m}, 1 \mathrm{H}), 2.18(\mathrm{q}, J=6.6 \mathrm{~Hz}, 2 \mathrm{H}), 1.6-$ $1.5(\mathrm{~m}, 4 \mathrm{H}), 1.28 \mathrm{ppm} \quad(\mathrm{t}, J=6.9 \mathrm{~Hz}, 3 \mathrm{H}) ;{ }^{13} \mathrm{C} \mathrm{NMR}(100 \mathrm{MHz}$, $\left.\left(\mathrm{CD}_{3}\right)_{2} \mathrm{CO}\right): \delta=168.6,157.8,145.8,138.7,138.2,136.1,134.6\left({ }^{2} J_{\mathrm{C}-\mathrm{F}}=\right.$ $32.5 \mathrm{~Hz}), 132.3,128.2,127.1,125.0\left({ }^{1} J_{\mathrm{C}-\mathrm{F}}=272.7 \mathrm{~Hz}\right), 123.8,119.4$, $118.6\left({ }^{3} J_{C-F}=4.9 \mathrm{~Hz}\right), 117.4,112.4,104.8,66.0,63.1,34.6,34.1,27.3$, 16.0 ppm; IR (NaCl): $\tilde{v}=3500-3200(\mathrm{br}, \mathrm{N}-\mathrm{H}$ and $\mathrm{O}-\mathrm{H}), 2935(\mathrm{~m}$, $\mathrm{C}-\mathrm{H}), 1675(\mathrm{~m}, \mathrm{C}=\mathrm{O}), 1591(\mathrm{~s}, \mathrm{C}=\mathrm{C}), 1532(\mathrm{~s}, \mathrm{C}=\mathrm{C}), 1329(\mathrm{~s}), 1266$ (s), $1177 \mathrm{~cm}^{-1}$ (s); MS (ESI+): $455[\mathrm{M}+\mathrm{Na}]^{+}(61), 433[\mathrm{M}+\mathrm{H}]^{+}(100)$; HRMS $(E S I+): m / z[M]^{+}$calcd for $\mathrm{C}_{23} \mathrm{H}_{24} \mathrm{~F}_{3} \mathrm{~N}_{2} \mathrm{O}_{3}: 433.1734$, found: 433.1731

\section{Biology}

Ligands and materials: SAHA (Merck; Rome, Italy), MS-275 (Bayer Schering AG; Berlin, Germany), and anacardic acid and CTPB (Alexis-Enzo Life Sciences; New York, USA) were dissolved in DMSO and used at $5 \times 10^{-6} \mathrm{M}$. All other compounds described were dissolved in DMSO (Sigma-Aldrich; Milan, Italy) and used at $5 \mu \mathrm{M}$ and $50 \mu \mathrm{M}$.

Cell Culture: Human U937 and HL60 leukaemia cell lines were propagated in RPMI medium supplemented with $10 \%$ fetal bovine serum (FBS; Hyclone, Milan, Italy) and antibiotics $\left(100 \mathrm{U} \mathrm{mL}^{-1}\right.$ penicillin, $100 \mu \mathrm{g} \mathrm{mL}^{-1}$ streptomycin and $250 \mathrm{ng} \mathrm{mL}^{-1}$ amphotericin-B). Cells were kept at the constant concentration of 200000 cells per $\mathrm{mL}$ of culture medium.

Cell Cycle Analysis: $2.5 \times 10^{5}$ U937 cells were collected and resuspended in $500 \mu \mathrm{L}$ of hypotonic buffer $(0.1 \%$ Triton X-100, $0.1 \%$ sodium citrate, $50 \mu \mathrm{g} \mathrm{mL}^{-1}$ propidium iodide, RNAse A). Cells were incubated in the dark for $30 \mathrm{~min}$. Data were acquired on a FACSCalibur flow cytometer using the CellQuest software (Becton, Dickinson \& Co.) and analysed with standard procedures also using CellQuest and the ModFit LT v3 software (Verity) as previously reported. ${ }^{[27]}$ Nuclear fragmentation (the so-called "sub-G1 DNA peak"), monitored by FACS and analysed by CellQuest technology, was used as an indicator of apoptosis.

Histone Extraction Protocol: Cells were harvested and washed twice with ice-cold phosphate-buffered saline (PBS) and lysed in Triton extraction buffer (TEB; PBS containing $0.5 \%$ Triton X-100 (v/v), $2 \mathrm{~mm}$ phenylmethylsulfonyl fluoride (PMSF), $0.02 \%(w / v) \mathrm{NaN}_{3}$ ) at a cellular density of $10^{7}$ cells per $\mathrm{mL}$ for $10 \mathrm{~min}$ on ice, with gentle stirring. After brief centrifugation at $2000 \mathrm{rpm}$ at $4{ }^{\circ} \mathrm{C}$, the supernatant was removed and the pellet was washed in half the volume of TEB and centrifuged as before. The pellet was resuspended in $0.2 \mathrm{M} \mathrm{HCl}$ at a cell density of $4 \times 10^{7}$ cells per $\mathrm{mL}$, and acid extraction was left to proceed overnight at $4^{\circ} \mathrm{C}$ on a rolling table. Next, the samples were centrifuged at $2000 \mathrm{rpm}$ for $10 \mathrm{~min}$ at $4{ }^{\circ} \mathrm{C}$, the supernatant was removed and the protein content was determined using the Bradford assay.

Western Blot analyses: Western Blot analyses were performed according to standard procedures following the suggestions of the antibody suppliers.

Determination of Histone $\mathrm{H} 3$ Specific Acetylation: For histone $\mathrm{H} 3$ acetylation in U937 cells, $5 \mu \mathrm{g}$ of histone extract were separated on $15 \%$ polyacrylamide gels and blotted. Western blots were shown for pan-acetylated histone H3 (Upstate Biotechnology; Milan, Italy).

Human recombinant CBP assay: The recombinant cyclic adenosine monophosphate response element-binding protein (CREB) binding protein (CBP) was prepared in E. coli BL21 and purified by affinity chromatography. The recombinant CBP fraction corresponded to amino acids 1098-1877. CBP was incubated in KAT buffer $\times 5$ (250 mм TRIS base pH 8.0, 50\% glycerol, 0.5 mм EDTA, 5 mм DTT) with $10 \mu \mathrm{g}$ of histone $\mathrm{H} 4$ peptide (corresponding to amino acids 2-24) and $20 \mu \mathrm{m}$ acetyl-CoA containing $0.5 \mu \mathrm{Ci} \mathrm{mL}^{-1}\left[{ }^{3} \mathrm{H}\right]$ acetyl-CoA in the presence of inhibitors and putative KAT activators. After $2 \mathrm{~h}$ a $37^{\circ} \mathrm{C}, 5 \mu \mathrm{L}$ of samples were spotted onto Whatman P81 paper (in triplicate). The paper squares were washed in $5 \%$ TCA $(\times 3)$ and $100 \%$ acetone $(\times 1)$ and then placed into scintillation vials containing scintillation fluid to allow the disintegrations per minute (dpm) reading. The dpm value of enzyme samples was compared with the dpm value of negative and positive controls. Data have been expressed as the percentage of activity considering the control without treatment as $100 \%$.

PCAF radioactive assay: $200 \mathrm{ng}$ of human PCAF were incubated in KAT buffer (Upstate Biotechnology) with $10 \mu \mathrm{g}$ of histone $\mathrm{H} 4$ peptide substrate (corresponding to amino acids 2-24) and $20 \mu \mathrm{m}$ acetyl-CoA containing $0.5 \mu \mathrm{CimL}^{-1}\left[{ }^{3} \mathrm{H}\right]$ acetyl-CoA. The acetylation reaction was performed in a volume of $25 \mu \mathrm{L}$ in the presence of test compounds at the desired final concentration. After $2 \mathrm{~h}$ a $37^{\circ} \mathrm{C}, 5 \mu \mathrm{L}$ of samples were spotted onto chromatographic Whatman P81 paper (in triplicate). After a washing session $(3 \times 5 \%$ TCA; $1 \times 100 \%$ acetone), the paper squares were placed into scintillation vials containing scintillation fluid to allow the $\mathrm{dpm}$ reading. The $\mathrm{dpm}$ value of enzyme samples was compared to the dpm value of the negative and positive controls and reported as the percentage of activity considering the untreated control as $100 \%$.

\section{Acknowledgements}

This work was partially supported by grants from the European Union (EPITRON, LSHC-CT2005-518417; ATLAS, 221952), AIRC, MICINN-Spain (SAF2007-63880-FEDER) and Xunta de GaliciaSpain (Inbiomed). 
Keywords: anacardic acid · chromatin - histone acetylation histone lysine acetyltransferases $\cdot$ salicylamides

[1] E. Ballestar, M. Esteller, Carcinogenesis 2002, 23, 1103-1109.

[2] P. M. Das, R. Singal, J. Clin. Oncol. 2004, 22, 4632-4642.

[3] S. B. Baylin, J. E. Ohm, Nat. Rev. Cancer 2006, 6, 107-116.

[4] S. Minucci, P. G. Pelicci, Nat. Rev. Cancer 2006, 6, 38-51.

[5] R. J. Klose, Y. Zhang, Nat. Rev. Mol. Cell Biol. 2007, 8, 307-318.

[6] T. Kouzarides, Cell 2007, 128, 693-705.

[7] S. D. Taverna, H. Li, A. J. Ruthenburg, C. D. Allis, D. J. Patel, Nat. Struct. Mol. Biol. 2007, 14, 1025-1040.

[8] J. A. Latham, S. Y. R. Dent, Nat. Struct. Mol. Biol. 2007, 14, 1017-1024.

[9] C. Choudhary, C. Kumar, F. Gnad, M. L. Nielsen, M. Rehman, T. C. Walther, J. V. Olsen, M. Mann, Science 2009, 325, 834-840.

[10] B. Li, M. Carey, J. L. Workman, Cell 2007, 128, 707-719.

[11] S. R. Bhaumik, E. Smith, A. Shilatifard, Nat. Struct. Mol. Biol. 2007, 14, $1008-1016$.

[12] M. Biel, V. Wascholowski, A. Giannis, Angew. Chem. 2005, 117, $3248-$ 3280; Angew. Chem. Int. Ed. 2005, 44, 3186-3216.

[13] P. A. Jones, S. B. Baylin, Cell 2007, 128, 683-692.

[14] A. G. Inche, N. B. La Thangue, Drug Discovery Today 2006, 11, 97-109.

[15] C. B. Yoo, P. A. Jones, Nat. Rev. Drug Discovery 2006, 5, 37-50.

[16] M. von Wantoch Rekowski, A. Giannis in Epigenetic Targets in Drug Discovery, (Eds.: W. Sippl, M. Jung), Wiley-VCH, Weinheim, 2009, pp. $243-$ 250.

[17] C. D. Allis, S. L. Berger, J. Cote, S. Dent, T. Jenuwein, T. Kouzarides, L. Pillus, D. Reinberg, Y. Shi, R. Shiekhattar, A. Shilatifard, J. L. Workman, Y. Zhang, Cell 2007, 131, 633-636.

[18] B. C. Smith, J. M. Denu, Biochim. Biophys. Acta, Gene Regul. Mech. 2009, $1789,45-57$.

[19] M. D. Shahbazian, M. Grundstein, Ann. Rev. Biochem. 2007, 76, 75-100.

[20] S. C. Hodawadekar, R. Marmorstein, Oncogene 2007, 26, 5528-5540.

[21] A. J. Bannister, T. Kouzarides, Nature 1996, 384, 641-643.

[22] V. V. Ogryzko, R. L. Schiltz, V. Russanova, B. H. Howard, Y. Nakatani, Cell 1996, 87, 953-959.

[23] C. A. Mizzen, X. J. Yang, T. Kokubo, J. E. Brownell, A. J. Bannister, T. Owen-Hughes, J. Workman, L. Wang, S. L. Berger, T. Kouzarides, Y. Nakatani, C. D. Allis, Cell 1996, 87, 1261-1270.

[24] X. Liu, L. Wang, K. Zhao, P. R. Thompson, Y. Hwang, R. Marmorstein, P. A. Cole, Nature 2008, 451, 846.

[25] Z. Wang, C. Zang, K. Cui, D. E. Schones, A. Barski, W. Peng, K. Zhao, Cell 2009, 138, 1019-1031.

[26] A. Insinga, S. Monestiroli, S. Ronzoni, V. Gelmetti, F. Marchesi, A. Viale, L. Altucci, C. Nervi, S. Minucci, P. G. Pelicci, Nat. Med. 2005, 11, 71-76.

[27] A. Nebbioso, N. Clarke, E. Voltz, E. Germain, C. Ambrosino, P. Bontempo, R. Alvarez, E. M. Schiavone, F. Ferrara, F. Bresciani, A. Weisz, A. R. de Lera, H. Gronemeyer, L. Altucci, Nat. Med. 2005, 11, 77-84.

[28] J. Wu, N. Xie, Z. Wu, Y. Zhang, Y. G. Zheng, Bioorg. Med. Chem. 2009, 17, $1381-1386$.
[29] E. M. Bowers, G. Yan, C. Mukherjee, A. Orry, L. Wang, M. A. Holbert, N. T. Crump, C. A. Hazzalin, G. Liszczak, H. Yuan, C. Larocca, S. A. Saldanha, R. Abagyan, Y. Sun, D. J. Meyers, R. Marmorstein, L. C: Mahadevan, R. M. Alani, P. A. Cole, Chem. Biol. 2010, 17, 471-482.

[30] K. Mantelingu, B. A. A. Reddy, V. Swaminathan, A. H. Kishore, N. B. Siddappa, G. V. P. Kumar, G. Naganshankar, N. Natesh, S. Roy, P. P. Sadhale, U. Ranga, C. Narayana, T. K. Kundu, Chem. Biol. 2007, 14, 645-657.

[31] K. Balasubramanyam, M. Altaf, R. A. Varier, V. Swaminathan, A. Ravindran, P. P. Sadhale, T. K. Kundu, J. Biol. Chem. 2004, 279, 33716-33726.

[32] K. Balasubramanyam, V. Swaminathan, A. Ranganathan, T. K. Kundu, J. Biol. Chem. 2003, 278, 19134-19140.

[33] L. Cui, J. Miao, T. Furuya, Q. Fan, X. Li, P. K. Rathod, X.-z. Su, L. Cui, Eukaryotic Cell 2008, 7, 1200-1210.

[34] K. Mantelingu, A. H. Kishore, K. Balasubramanyam, G. V. P. Kumar, M. Altaf, S. N. Swamy, R. Selvi, C. Das, C. Narayana, K. S. Rangappa, T. K. Kundu, J. Phys. Chem. B 2007, 111, 4527-4534.

[35] J. A. Souto, M. Conte, R. Alvarez, A. Nebbioso, V. Carafa, L. Altucci, A. R. de Lera, ChemMedChem 2008, 3, 1435-14426.

[36] R. Costi, R. DiSanto, M. Artico, G. Miele, P. Valentini, E. Novellino, A. Cereseto, J. Med. Chem. 2007, 50, 1973-1977.

[37] S. Kotha, K. Lahiri, D. Kashinath, Tetrahedron 2002, 58, $9633-9695$.

[38] N. Miyaura, T. Ishiyama, H. Sasaki, M. Sihikama, M. Sato, A. Suzuki, J. Am. Chem. Soc. 1989, 111, 314

[39] A. Hadfield, H. Schweitzer, M. P. Trova, K. Green, Synth. Commun. 1994, 24, 1025-1028.

[40] R. G. Dushin, S. J. Danishefsky, J. Am. Chem. Soc. 1992, 114, 655-659.

[41] J. H. P. Tyman, Chem. Soc. Rev. 1979, 8, 499-537.

[42] A. Fürstner, I. Konetzki, Tetrahedron 1996, 52, 15071-15075.

[43] G. A. Molander, F. Dehmel, J. Am. Chem. Soc. 2004, 126, 10313-10318.

[44] T. Okazoe, K. Takai, K. Utimoto, J. Am. Chem. Soc. 1987, 109, $951-952$.

[45] A. Fürstner, Chem. Rev. 1999, 99, $991-1046$.

[46] H. C. Brown, S. K. Gupta, J. Am. Chem. Soc. 1972, 94, 4370-4371.

[47] W. R. Roush, M. Kageyama, R. Riva, B. B. Brown, J. S. Warmus, K. J. Moriarty, J. Org. Chem. 1991, 56, 1192-1210.

[48] K. Olofsson, M. Larhed in Microwave-Assisted Organic Synthesis, (Eds.: J. P. Tierney, P. Lidström), Blackwell Publishing Ltd., Oxford, 2005, Chapter 2 .

[49] N. E. Leadbeater, M. Marco, J. Org. Chem. 2003, 68, 888-892.

[50] N. Khan, M. Jeffers, S. Kumar, C. Hackett, F. Boldog, N. Khramtsov, X. Qian, E. Mills, S. C. Berghs, N. Carey, P. W. Finn, L. S. Collins, A. Tumber, J. W. Ritchie, P. B. Jensen, H. S. Lichenstein, M. Sehested, Biochem. J. 2008, 409, 581-589.

[51] E. D. Eliseeva, V. Valkov, M. Jung, M. O. Jung, Mol. Cancer. Ther. 2007, 6, $2391-2398$.

Received: April 15, 2010

Revised: June 30, 2010

Published online on August 3, 2010 